\title{
Water consumption and water-saving characteristics of a ground cover rice production system
}

\author{
Xinxin Jin ${ }^{\mathrm{a}}$, Qiang Zuo ${ }^{\mathrm{a}}$, Wenwen Ma ${ }^{\mathrm{a}}$, Sen $\mathrm{Li}^{\mathrm{a}}$, Jianchu Shi ${ }^{\mathrm{a}, *}$, Yueyue Tao ${ }^{\mathrm{a}}$, Yanan Zhang ${ }^{\mathrm{a}}$, Yang Liu ${ }^{\mathrm{b}}$, \\ Xiaofei Liu ${ }^{\mathrm{c}}$, Shan Lin ${ }^{\mathrm{a}}$, Alon Ben-Gal ${ }^{\mathrm{d}}$ \\ ${ }^{a}$ College of Resources and Environmental Sciences, China Agricultural University, Key Laboratory of Plant-Soil Interactions, Ministry of Education, and Key Laboratory of Arable \\ Land Conservation (North China), Ministry of Agriculture, Beijing 100193, China \\ ${ }^{\mathrm{b}}$ The Second Water Conservancy and Hydropower Survey \& Design Institute of Hebei Province, Shijiazhuang 050021, China \\ ${ }^{c}$ Institute of Geographical Sciences and Natural Resources Research, Chinese Academy of Sciences, Beijing 100101, China \\ ${ }^{\mathrm{d}}$ Soil, Water and Environmental Sciences, Agricultural Research Organization, Gilat Research Center, Mobile Post Negev 85280, Israel
}

\section{A R T I C L E I N F O}

\section{Article history:}

Received 1 June 2015

Received in revised form 25 April 2016

Accepted 6 June 2016

Available online 16 June 2016

This manuscript was handled by Peter K.

Kitanidis, Editor-in-Chief, with the

assistance of Nunzio Romano, Associate

Editor

\section{Keywords:}

Water consumption

Water use efficiency

Water balance

Transpiration

Deep drainage

Oryza sativa

\section{S U M M A R Y}

The ground cover rice production system (GCRPS) offers a potentially water-saving alternative to the traditional paddy rice production system (TPRPS) by furrow irrigating mulched soil beds and maintaining soils under predominately unsaturated conditions. The guiding hypothesis of this study was that a GCRPS would decrease both physiological and non-physiological water consumption of rice compared to a TPRPS while either maintaining or enhancing production. This was tested in a two-year field exper-

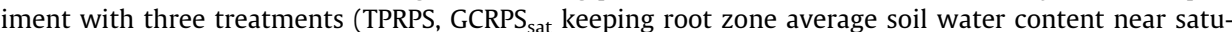
rated, and GCRPS ${ }_{80 \%}$ keeping root zone average soil water content as $80-100 \%$ of field water capacity) and a greenhouse experiment with four treatments (TPRPS, GCRPS sat $_{\text {, GCRPS }}$ fwc keeping root zone average soil water content close to field water capacity, and GCRPS $_{80 \%}$ ). The water-saving characteristics of GCRPS were analyzed as a function of the measured soil water conditions, plant parameters regarding growth and production, and water input and consumption. In the field experiment, significant reduction in both physiological and non-physiological water consumption under GCRPS lead to savings in irrigation water of $\sim 61-84 \%$ and reduction in total input water of $\sim 35-47 \%$. Compared to TPRPS, deep drainage was reduced $\sim 72-88 \%$, evaporation was lessened $\sim 83-89 \%$ and transpiration was limited $\sim 6-10 \%$ under GCRPS. In addition to saving water, plant growth and grain yield were enhanced under GCRPS due to increased soil temperature in the root zone. Therefore, water use efficiencies (WUEs), based on transpiration, irrigation and total input water, were respectively improved as much as $27 \%, 609 \%$ and $110 \%$ under GCRPS. Increased yield attributed to up to $\sim 19 \%$, decreased deep drainage accounted for $\sim 75 \%$, decreased evaporation accounted for $\sim 14 \%$ and reduced transpiration for $\sim 5 \%$ of the enhancement in WUE of input water under GCRPS, while increased runoff and water storage had negative influence on WUE ( -7.5 and $-3.7 \%$, respectively) for GCRPS compared to TPRPS. The greenhouse experiment validated the results obtained in the field by simplifying the non-physiological water consumption processes, and thus confirming the relative importance of physiological processes and increased WUE under GCRPS.

(c) 2016 Elsevier B.V. All rights reserved.

\section{Introduction}

Rice (Oryza sativa L.) is one of the most important grain crops for almost half the world's population, and it is predicted that an annual increase of $8-10$ million tons in rice production will be required to meet future needs (IRRI, 2011). Nevertheless, 15-20 million ha of rice will likely suffer from drought stress by 2025

\footnotetext{
* Corresponding author.

E-mail addresses: jinxinxin1984@163.com (X. Jin), qiangzuo@cau.edu.cn (Q. Zuo), shijianchu@cau.edu.cn (J. Shi), bengal@volcani.agri.gov.il (A. Ben-Gal).
}

due to water scarcity resulting from increasing competition from urban and industrial water utilization (Belder et al., 2005; Bouman, 2007). As the largest rice producer and consumer in the world, China cultivates 29 million ha of rice, representing about $30 \%$ of its total farmland and about $70 \%$ of its total agricultural water resource consumption (FAOSTAT, 2011). Water shortage in China is estimated to reach 400 billion $\mathrm{m}^{3}$ by 2050 , roughly representing $80 \%$ of its current annual capacity (Tso, 2004). Therefore, exploration of rice production technologies to meet the requirements of increased production coupled with decreased water consumption is imperative. 
Currently, most rice in the world is cultured using the traditional paddy rice production system (TPRPS) (Bouman and Tuong, 2001; Cabangon et al., 2002), in which water consumption per unit area is about 3-5 times that of alternative dry-land crop production systems (Bouman and Tuong, 2001). Over the last decades, several innovative technologies have been developed to reduce water consumption for rice cultivation (Peng et al., 1999; Belder et al., 2004; Liu et al., 2005). The ground cover rice production system (GCRPS), proposed in 1980s (Lin et al., 2002), has been found to reduce water application, enhance soil temperature, inhibit weed growth, and increase rice production (Fan et al., 2005; Liu et al., 2005, 2013; Tao et al., 2006; Li et al., 2007; Qu et al., 2012) and is therefore regarded as one of the most promising watersaving technologies for rice (IRRI, 2011). The GCRPS is currently applied on more than 4 million ha in China (Tao et al., 2015). In a GCRPS, strip soil beds are mulched by plastic film or crop straw, and rice, irrigated via the furrows between soil beds, is cultivated in predominantly unsaturated soil (Qu et al., 2012). However, knowledge regarding the water consumption and water-saving characteristics of GCRPS, essential for its improvement and application to irrigation scheduling, is insufficient.

In a soil-plant system, water consumption can be divided into physiological (e.g. transpiration) and non-physiological (e.g. evaporation, deep drainage, runoff, and increase in water storage) components. Physiological consumption is commonly regarded as effective while non-physiological losses are considered ineffective water use (Bouman and Tuong, 2001). In a TPRPS without runoff, only about $30 \%$ of the total input water is consumed effectively through transpiration, whereas the remainder is lost through deep drainage (about 57\%) and evaporation (about 13\%) (Bouman et al., 2005). The most significant aspects discriminating TPRPS from GCRPS lie in the transformation of root zone soil water status from completely saturated and anaerobic to partially unsaturated and aerobic and the additional coverage on the soil beds. Consequently, deep drainage and evaporation are expected to be substantively decreased in a GCRPS (Peng et al., 1999). However, evaporation and deep drainage in GCRPS reported in the literature have only been analyzed qualitatively (Fan et al., 2002; Liu et al., 2005; Tao et al., 2006, 2015). Due to the mulch on the soil beds, the lower than field capacity soil water content and previously published data (Li et al., 2000; Huang et al., 2003), evaporation and deep drainage were assumed negligible for cases where quantification was required for water balance evaluation in a GCRPS. In fact, while it would be reasonable to neglect the evaporation from soil beds mulched by plastic film, evaporation is expected to occur from the furrows, where water is consistently or intermittently maintained for irrigation. Deep drainage, driven by the gradient of soil water potential, will almost always takes place even in the unsaturated lower root zone (Qin et al., 2006; Bouman et al., 2007).

Physiological water consumption in a GCRPS is also expected to be influenced due to its alteration of root zone conditions and probable effects on rice growth (Allen et al., 1998; Bouman et al., 2005). Significant reduction in evapotranspiration has been reported for GCRPS when compared to TPRPS (Li et al., 2000; Huang et al., 2003) but this could be simply due to reduced evaporation. Regarding just transpiration there is little published information. Relative to TPRPS, significant limitation on leaf stomatal conductance has been observed under GCRPS due to drought stress (Yang et al., 2007; Zhang et al., 2008, 2009). In contrast, leaf area under GCRPS has been found to be greatly enlarged as a result of increased soil temperature (Tao et al., 2006; Xu et al., 2007; Qu et al., 2012). The overall effect of GCRPS on plant transpiration is therefore still unknown.

Water use efficiency (WUE), defined at different scales for different water related parameters, is an important evaluator of the water-saving characteristics of a crop production system (Belder et al., 2005; Bouman, 2007; Ali and Talukder, 2008; Qiu et al., 2008). At a field-scale, WUE is usually used to evaluate the practical productivity of total input water as (Bouman et al., 2007; Sudhir et al., 2011):

$W U E_{I+P}=1000 \times Y /(I+P)$

where $W U E_{I+P}$ is the WUE of input water (including irrigation and precipitation) $\left(\mathrm{kg} \mathrm{m}^{-3}\right) ; Y$ is the grain yield $\left(\mathrm{kg} \mathrm{m}^{-2}\right) ; I$ is the irrigation amount $(\mathrm{mm}) ; P$ is the precipitation $(\mathrm{mm})$; the number of 1000 is the unit conversion factor from $\mathrm{m}$ to $\mathrm{mm}$. When precipitation is negligible or similar under various situations, Eq. (1) can be simplified to compare the practical productivity of irrigation water as (Qin et al., 2006; Sudhir et al., 2011):

$W U E_{I}=1000 \times Y / I$

where $W U E_{I}$ is the WUE of irrigation water $\left(\mathrm{kg} \mathrm{m}^{-3}\right)$. At a plantscale, WUE is also widely adopted to describe the relationship between physiological water consumption and photosynthetic product as (Hsiao, 1993; Shi et al., 2014):

$W U E_{T}=1000 \times B_{a} / T$

where $W U E_{T}$ is the WUE of transpiration water $\left(\mathrm{kg} \mathrm{m}^{-3}\right) ; B_{a}$ is the total dry biomass of crop, sometimes including only the aboveground biomass $\left(\mathrm{kg} \mathrm{m}^{-2}\right)$; $T$ is the transpiration $(\mathrm{mm})$. Generally speaking, either $W U E_{I}$ or $W U E_{I+P}$ reflects the combined efficiency of both physiological and non-physiological water consumption, while $W U E_{T}$ exclusively implies the efficiency of physiological water consumption. Up to now, many studies have evaluated the WUE of GCRPS with $W U E_{I+P}$ and $W U E_{I}$ rather than $W U E_{T}$, and indicated an increase of $70-106 \%$ and $273-520 \%$ in comparison to TPRPS, respectively (Fan et al., 2005; Liu et al., 2005; Tao et al., 2006, 2015; Li et al., 2007; Xu et al., 2007; Zhang et al., 2008).

The guiding hypothesis of this study was that a GCRPS would decrease both physiological and non-physiological water consumption in comparison to a TPRPS while maintaining or enhancing rice production. The objective was to test this hypothesis by quantifying water consumption and WUE in field trials and greenhouse soil column experiments through comparing GCRPS with TPRPS.

\section{Materials and methods}

\subsection{Field experiment (Exp. 1)}

\subsubsection{Experimental conditions and treatments}

A field experiment was conducted from April to September (the local growing season of rice) in both 2013 and 2014 at a farm of the Fangxian Agricultural Bureau (32 $07^{\prime} 11^{\prime \prime} \mathrm{N}, 110^{\circ} 42^{\prime} 45^{\prime \prime} \mathrm{E}$, and altitude $440 \mathrm{~m}$ ), Shiyan, Hubei province, China. The experimental site was located in the Qinbashan Mountains with a northern subtropical monsoon climate condition. As one of the main crops in this region, rice often suffers from low temperatures during its early growing season and can face seasonal water scarcity in spite of a local annual average rainfall reaching $830 \mathrm{~mm}$ (Liu et al., 2013; Tao et al., 2015). For example, the average rainfall of about $100 \mathrm{~mm}$ during April and May (the early growing season of rice) from 2009 to 2014 is less than $20 \%$ of the rainfall throughout the growing season, representing less than half of the total water requirement for TPRPS.

The average air temperature and solar radiation (WeatherHawk 500, Campbell Scientific, USA) from transplantation to harvest were $23.6{ }^{\circ} \mathrm{C}$ and $9.4 \mathrm{MJ} \mathrm{m}^{-2} \mathrm{~d}^{-1}$ in 2013 , and $22.2^{\circ} \mathrm{C}$ and $6.7 \mathrm{MJ} \mathrm{m}^{-2} \mathrm{~d}^{-1}$ in 2014. Grain maturity was delayed around one week in 2014 compared to 2013. The soil profile from 0 to $60 \mathrm{~cm}$ contained two layers of silt loam (0-20 and $20-60 \mathrm{~cm})$, with a 
Table 1

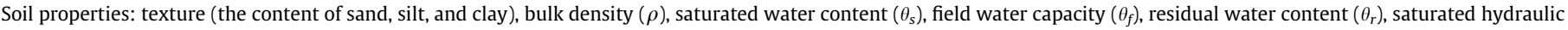
conductivity $\left(K_{s}\right)$, and the fitting parameters in van Genuchten's (1980) soil water retention curve $(\alpha$ and $n)$ in Exps. 1 and 2.

\begin{tabular}{|c|c|c|c|c|c|c|c|c|c|c|c|}
\hline Experiments & Depth (cm) & Sand (\%) & Silt (\%) & Clay (\%) & $\rho\left(\mathrm{g} \mathrm{cm}^{-3}\right)$ & $\theta_{s}\left(\mathrm{~cm}^{3} \mathrm{~cm}^{-3}\right)$ & $\theta_{f}\left(\mathrm{~cm}^{3} \mathrm{~cm}^{-3}\right)$ & $\theta_{r}\left(\mathrm{~cm}^{3} \mathrm{~cm}^{-3}\right)$ & $K_{s}\left(\mathrm{~mm} \mathrm{~d}^{-1}\right)$ & $\boldsymbol{\alpha}\left(\mathrm{cm}^{-1}\right)$ & $n$ \\
\hline Exp. 1 & $0-20$ & 20.25 & 59.98 & 19.77 & 1.36 & 0.464 & 0.409 & 0.076 & 69.2 & 0.003 & 1.253 \\
\hline & $20-60$ & 17.66 & 64.96 & 17.39 & 1.53 & 0.473 & 0.382 & 0.081 & 4.5 & 0.006 & 1.182 \\
\hline Exp. 2 & $0-45$ & 32.89 & 43.53 & 23.58 & 1.35 & 0.505 & 0.243 & 0.051 & 41.8 & 0.085 & 1.303 \\
\hline
\end{tabular}

$\mathrm{pH}$ of about 6.0. The parameters regarding soil texture and hydraulic property are shown in Table 1 . Soil water retention was measured by a pressure membrane plate (Soil Moisture Equipment Co., USA) and described with the closed form of van Genuchten (1980). Field water capacity $\left(\theta_{f}, \mathrm{~cm}^{3} \mathrm{~cm}^{-3}\right)$ was chosen corresponding to the soil matric potential of $-300 \mathrm{~cm}$ for silt loam (Romano and Santini, 2002). During the entire growing season, the ground water table, measured every 15 days in 2013 and every 10 days in 2014, mainly fluctuated between 40 and $70 \mathrm{~cm}$ depth from the soil surface.

For rice cultivation, 9 independent plots $(900 \mathrm{~cm}$ wide by $1000 \mathrm{~cm}$ long) were prepared before transplanting (Fig. 1a). To avoid lateral water percolation between neighbor plots, seepageproof film was buried around each plot to the depth of $80 \mathrm{~cm}$ from the soil surface. All the plots were steeped and subsequently plowed to a depth of $20 \mathrm{~cm}$. Five strip soil beds, $156 \mathrm{~cm}$ wide by

a

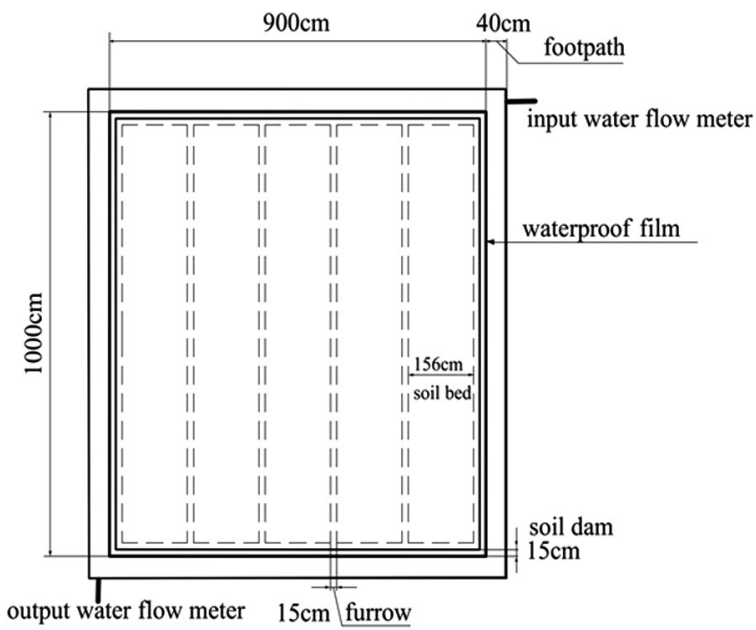

b
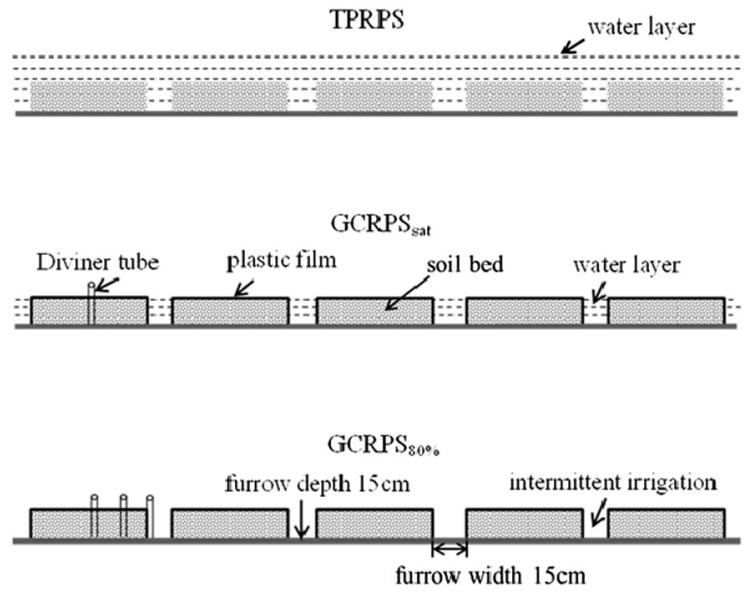

Fig. 1. Diagram of (a) plots and (b) irrigation treatments in Exp. 1. TPRPS, traditional paddy rice production system; GCRPS $_{\text {sat }}$, ground cover rice production system (GCRPS) with nearly saturated water content in root zone; GCRPS ${ }_{80 \%}$, GCRPS with $80-100 \%$ of field water capacity in root zone.
$940 \mathrm{~cm}$ long, were built in each plot. Small furrows, $15 \mathrm{~cm}$ wide by $15 \mathrm{~cm}$ deep, were dug adjacent to each soil bed (Fig. 1b). After the application of basal fertilizers $\left(150 \mathrm{~kg} \mathrm{~N} \mathrm{ha}^{-1}\right.$ as urea, $45 \mathrm{~kg} \mathrm{P} \mathrm{ha}{ }^{-1}$ as calcium superphosphate and $45 \mathrm{~kg} \mathrm{~K} \mathrm{ha}^{-1}$ as potassium chloride) in each plot, 6 plots were randomly chosen and their soil beds covered by plastic film. Rice seeds ( $O$. sativa $\mathrm{L}$. cv. Yixiang 3728) were initially sowed in a nursery field on 2 April in 2013 and 5 April in 2014 to prepare seedlings. On 28 April in 2013 and 29 April in 2014, rice seedlings were transplanted into the soil beds at $26 \times 18 \mathrm{~cm}^{2}$ spacing, at a rate of two plants per hill. Rice was harvested on 10 September 2013 (135 days after transplanting, 135 DAT) and 19 September 2014 (143 DAT), after which the plastic film was removed manually.

Water level was measured using vertically placed rulers located at five random locations in the furrows of each plot. Three treatments were applied with three replicates (Fig. 1b). In the three plots without plastic film for treatment TPRPS, irrigation was applied in order to maintain a measured average thickness of water on the soil beds between 2 and $5 \mathrm{~cm}$. Three plots with plastic film were irrigated through the furrows without a water layer on the soil beds themselves, keeping the measured average thickness of water in the furrows between 10 and $15 \mathrm{~cm}$. Since the root zone (0-40 cm soil layer) average soil water content was close to saturation, this treatment was named GCRPS $_{\text {sat }}$. The remaining three plots with plastic film were managed identically to GCRPS sat before mid-tillering stage (34 DAT), and then transient irrigation was intermittently implemented to completely fill the furrows when the measured root zone averaged water content reached approximately $80 \%$ of field capacity. This treatment, maintaining root zone average soil water content between $80 \%$ and $100 \%$ of field water capacity, was named GCRPS $80 \%$. During the traditional drying field periods (one week during the late max-tillering and two weeks before harvest), irrigation was suspended. Under TPRPS, a maximum water layer of $10 \mathrm{~cm}$ on the soil beds was permitted to effi-

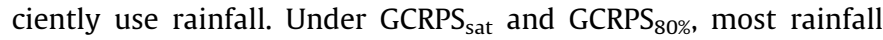
was drained out to keep the soil beds non-flooded in 2013, while a maximum water layer of $1 \mathrm{~cm}$ on the soil beds was permitted in 2014 to utilize more rainfall.

\subsubsection{Plant samplings and measurements}

The soil water content under GCRPS was measured every 2 days with a capacitance probe (Diviner 2000, Sentek, Australia) at $10 \mathrm{~cm}$ intervals from surface to $60 \mathrm{~cm}$ depth. For each plot under GCRPS $_{\text {sat }}$, one access tube $(100 \mathrm{~cm}$ in length and $5 \mathrm{~cm}$ in diameter) was fixed at the center of a soil bed to a depth of $80 \mathrm{~cm}$. For each plot under GCRPS $_{80 \%}$, three access tubes were uniformly fixed at the center, quarter and margin of a soil bed at $39 \mathrm{~cm}$ intervals (Fig. 1b). Under each treatment, soil temperatures at the depths of 5 (with 3 replications), 10 and $20 \mathrm{~cm}$ (only one replication) were measured hourly by a multipoint temperature instrument (CB0221, Yaxin, China). Before 20 DAT, the decrease of water level on the soil beds or in the furrows was measured for each plot during the nighttime from 18:00 to 6:00 to estimate the rate of deep drainage. A pan $(20 \mathrm{~cm}$ in diameter) was placed under canopy to measure evaporation from the water surface in each plot and was weighted daily at $6: 00$ in 2013 , and at both 6:00 and 18:00 in 2014. 
Plants were sampled during the mid-tillering, max-tillering, panicle initiation, anthesis, and maturity stages $(34,53,78,99$ and 135 DAT in 2013; 34, 51, 78, 99 and 143 DAT in 2014). For each sampling time, 8 hills of rice $\left(0.4 \mathrm{~m}^{2}\right)$ were removed from each plot. Leaf area was evaluated using leaf length, width and a conversion coefficient of 0.75 (van Arkel, 1978), and above ground biomass was determined after oven-drying at $70^{\circ} \mathrm{C}$ to a constant weight. The roots of three hills in each plot for the last sampling in 2013 and one hill in each plot for each sampling in 2014 were excavated with a steel column $(15 \mathrm{~cm}$ in diameter and $50 \mathrm{~cm}$ in length) at $5 \mathrm{~cm}$ intervals from surface to $20 \mathrm{~cm}$ depth and at $10 \mathrm{~cm}$ intervals from $20 \mathrm{~cm}$ downwards. Roots in each soil layer were washed via a $0.05 \mathrm{~cm}$ diameter sieve, scanned (SNAPSCAN 1236, AGFA, Germany) and analyzed with the WinRHIZO software package (Regent Instruments Inc., Canada) for root length, diameter and surface area. Root dry weight was determined by ovendrying to a constant weight at $70^{\circ} \mathrm{C}$. For the first 4 sampling events, one hill in each plot was randomly chosen to measure the stomatal conductance of flag leaves between 9:00 and 11:00 with a portable photosynthesis system (Li-6400, Li-Cor, USA) under photosynthetic active radiation of $1400-1600 \mu \mathrm{mol} \mathrm{m}^{-2} \mathrm{~s}^{-1}$. At harvest, grain yield for each plot was measured in the central bed $\left(10 \mathrm{~m}^{2}\right)$, undisturbed by plant samplings. During the maxtillering stage in 2013 (Tao et al., 2015) and the max-tillering and panicle initiation stages in 2014, the sampled flag leaves were analyzed for stable carbon isotope composition $\left(\delta^{13} \mathrm{C}\right)$ using stableisotope mass spectrometry (Thermo Scientific, Waltham, MA, USA).

Leaf area index was defined as the ratio of leaf area to soil surface area, and the corresponding effective leaf area index $\left(L A I_{e}\right)$ was estimated to consider the effect of light interception on transpiration as follows (Ben-Mehrez et al., 1992):

$L A I_{e}=\frac{L A I}{(0.3 L A I+1.2)}$

\subsubsection{Water balance analysis}

During any balance period, water input should be equal to water consumption (Sudhir et al., 2011):

$P+I=T+R+E+D+\Delta W$

where $T, R$ and $E$ are plant transpiration, runoff and evaporation, respectively $(\mathrm{mm}) ; D$ is deep drainage $(\mathrm{mm})$, i.e. the water percolated from the root zone to the deeper soil; $\Delta W$ is the increase of water storage (including water on the soil beds or in the furrows and soil water stored in the root zone, $\mathrm{mm}$ ).

In this experiment, precipitation was obtained directly from the automatic weather device. Irrigation and runoff were calculated according to data recorded by the water-flow meters and the net area of each plot $\left(A_{p}=84.39 \mathrm{~m}^{2}\right)$. The increase in water storage was estimated according to the measured soil water contents in the root zone under unsaturated conditions (e.g. during the drying field period under TPRPS and GCRPS sat, and from mid-tillering to maturity stage under GCRPS $_{80 \%}$ ) or water layer depth on soil beds or in furrows under saturated or near saturated conditions (e.g. from transplanting to maturity stage except the drying field periods under TPRPS and GCRPS sat $_{\text {, }}$ and from transplanting to midtillering stage under GCRPS $_{80 \%}$ ).

Deep drainage was calculated as (Hasegawa and Eguchi, 2002):

$D=\int_{t=T_{0}}^{t=T_{1}} q(t) \mathrm{d} t$

where $t$ was time (d); $T_{0}$ and $T_{1}$ were the initial and terminal times for balance calculation, respectively (d); $q(t)$ was the deep drainage rate through the lower boundary of root zone $\left(\mathrm{mm} \mathrm{d}^{-1}\right)$. Under saturated or near saturated conditions, the effects of macro-pores (e.g. the seams along the seepage-proof film) or a soil layer with little water conductivity (e.g. plow pan) on deep drainage might be significant (Gerke, 2006; Koestel and Larsbo, 2014), and thus Darcy's law was unreliable to describe $q(t)$ with the soil water conductivity measured at certain position (Beven, 1995; Alaoui, 2015). Since there was little fluctuation of water table on the soil beds or in the furrows under saturated or near saturated conditions, $q(t)$ was assumed to be constant and estimated during nighttime when evaporation, transpiration and the decrease of water level were determined and there was no irrigation, rainfall or runoff. Before 20 DAT, plant transpiration during nighttime was assumed to be negligible (Crago, 1996; Gentine et al., 2011). Measured seasonal evaporation rate from $18: 00$ to $6: 00$ was only $0.18 \mathrm{~mm} \mathrm{~d}^{-1}$ in 2014 , corresponding to $11.2 \%$ of that from $6: 00$ to $18: 00$. Nighttime evaporation was therefore neglected in the water balance calculations for deep drainage. Its rate $q(t)$ was then estimated as follows:

$q(t)=\frac{d_{d}(t) A_{w}}{A_{p} \Delta t}$

where $d_{d}(t)$ was the measured decrease of water level ( $\mathrm{mm}$ ) on the soil beds (under TPRPS) or in the furrows (under GCRPS $_{\text {sat }}$ and GCRPS $_{80 \%}$ ) from 18:00 to 6:00 before 20 DAT; $A_{w}$ was the area of water surface $\left(\mathrm{m}^{2}\right)$, equaling the net area of plot $A_{p}$ under TPRPS $\left(84.39 \mathrm{~m}^{2}\right)$ and the projected area of furrows under GCRPS GCRPS $_{80 \%}\left(11.07 \mathrm{~m}^{2}\right) ; \Delta t$ was the time interval between two successive measurements for water level (d), and equaled to $0.5 \mathrm{~d}$. For each plot, the $q(t)$ calculated with Eq. (7) was very stable during the first 20 days after transplanting, thus its average was used to estimate the deep drainage under saturated or near saturated conditions through Eq. (6).

Under unsaturated conditions, the effects of plow pan and macro-pores on soil water flow rate at the lower boundary of root zone were ignored (Crawford, 1994), and $q(t)$ was calculated according to Darcy's law (Chen and Liu, 2002; Wang et al., 2006):

$q(t)=-K(h)\left(\frac{d h}{d z}-1\right)$

where $h(\mathrm{~cm})$ was the soil matric potential at the lower boundary of root zone, determined according to the measured soil water content and the soil water retention curve; $K(h)$ was the soil hydraulic conductivity $\left(\mathrm{mm} \mathrm{d}^{-1}\right) ; z$ was the vertical coordinate originating from soil surface and positive downward $(\mathrm{cm})$. During the drying field periods, since the soil water content under TPRPS was not measured, the corresponding $q(t)$ was approximated as the calculated value under GCRPS sat due to their similar soil water environments before drying field.

Under saturated or near saturated conditions, evaporation occurring from the water surface during a balance period was estimated as:

$E=\int_{t=T_{0}}^{t=T_{1}} \frac{e_{w}(t) A_{w}}{A_{p}} \mathrm{~d} t$

where $e_{w}(t)$ was the rate of water surface evaporation measured by a pan $\left(\mathrm{mm} \mathrm{d}^{-1}\right)$. Under unsaturated conditions, evaporation from the uncovered soil surfaces (e.g. the dried furrows and the soil beds under TPRPS) was estimated as:

$E=\int_{t=T_{0}}^{t=T_{1}} \frac{e_{s}(t) A_{s}}{A_{p}} \mathrm{~d} t$

where $A_{s}$ was the area of the uncovered soil surface $\left(\mathrm{m}^{2}\right)$ and equal to $A_{w} ; e_{s}(t)$ was the rate of soil surface evaporation $\left(\mathrm{mm} \mathrm{d}^{-1}\right)$. Under $\mathrm{GCRPS}_{80 \%}, e_{s}(t)$ from the unsaturated furrows was estimated through Darcy's law using water content measured at the two points closest to the soil surface (Gardner, 1958; Schneider et al., 2010). During the drying field periods, $e_{s}(t)$ from the uncovered soil 
beds or furrows under TPRPS and GCRPS sat $_{\text {was assumed to be equal }}$ to that under GCRPS $_{80 \%}$ due to the similar changing processes of soil water distributions.

Following determination of the water balance components as described (e.g. precipitation, irrigation, runoff, evaporation, deep drainage and increase in water storage), plant transpiration during any given period was calculated according to Eq. (5).

\subsection{Greenhouse experiment (Exp. 2)}

\subsubsection{Experimental conditions and treatments}

A greenhouse experiment (Exp. 2), allowing a simple water balance and robust quantification of non-physiological components, was conducted to confirm the effect of GCRPS on physiological water-saving characteristics found in Exp. 1. Initially, 48 columns (36 for the treatment of GCRPS, and the other 12 for TPRPS) made of polyvinyl chloride (PVC) pipes were prepared $(50 \mathrm{~cm}$ in depth and $15 \mathrm{~cm}$ in diameter). Each column was cleaved vertically into two halves, and then the cleaved parts were reattached and sealed with a PVC cover at the bottom. Columns were filled to $45 \mathrm{~cm}$ height with loam soil at a bulk density of $1.35 \mathrm{~g} \mathrm{~cm}^{-3}$. The soil water retention was measured and described as that described in Exp. 1, and the field water capacity $\left(\theta_{f}\right)$ was chosen corresponding to the soil matric potential of $-200 \mathrm{~cm}$ for loam soil (Romano and Santini, 2002) (Table 1). In each column, base fertilizer was applied as described in Exp. 1, and the soil surfaces of 36 columns for GCRPS were covered by plastic film. A single germinated rice $(O$. sativa L. cv. Yixiang 3728) seed was directly transplanted into each column on 8 May in 2013, and cultivated to 15 August (totally 99 days, 99 DAT). During the entire experimental period, the average temperature and radiation in the greenhouse were $20.6^{\circ} \mathrm{C}$ and $5.67 \mathrm{MJ} \mathrm{m}^{-2} \mathrm{~d}^{-1}$, respectively.

Plants were uniformly cultured with a thin water layer over the soil surface until 22 DAT, when four specific irrigation treatments were initialized. The three treatments of TPRPS, GCRPS GCRPS $_{80 \%}$ were managed as described in Exp. 1 but without a drying field period. The remaining treatment (12 columns covered by plastic film) was GCRPS fwc $_{\text {, }}$ under which the root zone average soil water content was maintained from $\theta_{f}$ to $120 \% \theta_{f}$.

\subsubsection{Samplings and measurements}

Soil temperature at the depth of $10 \mathrm{~cm}$ from the soil surface under each treatment was monitored as described for Exp. 1. Three columns under each treatment were chosen and weighed daily at 18:00, and the daily evapotranspiration $(\mathrm{mm})$ was determined according to the loss of water and the soil surface area of the column. Under TPRPS, daily water surface evaporation ( $\mathrm{mm}$ ) was measured by a pan ( $15 \mathrm{~cm}$ in diameter) located under the canopies. A total of 4 sampling events were carried out on 39, 59, 79 and 99 DAT, corresponding to the main growth stages of early tillering, mid-tillering, max-tillering, and panicle initiation, respectively. Each sampling event was conducted on a sunny day, utilizing 3 randomly selected columns under each treatment. After measuring stomatal conductance of flag leaves, the shoots were removed, and leaf area and dry biomass were measured as described for Exp. 1. The sampled flag leaves during the max-tillering and panicle initiation stages were also analyzed for $\delta^{13} \mathrm{C}$ as described for Exp. 1. The columns were opened to sample soil from the surface to rooting depth at $5 \mathrm{~cm}$ intervals. Sampled soil was dried to constant at $105{ }^{\circ} \mathrm{C}$ to determine the gravimetric water content, which was subsequently transformed to the volumetric water content according to the soil bulk density. The roots in the rest of soil in each soil layer were washed and dried as described for Exp. 1.

\subsubsection{Water balance analysis}

Due to the absence of rainfall, runoff and deep drainage, water balance calculation in Exp. 2 was much simpler than that in Exp. 1. Under TPRPS, transpiration was directly estimated by subtracting the measured water surface evaporation from evapotranspiration. Since the soil surface was completely covered by plastic film, the

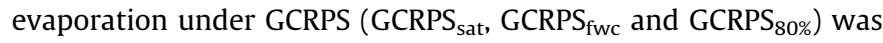
ignored, and measured evapotranspiration was assumed equal to transpiration.

\subsection{Statistical analysis}

Analysis of variance (ANOVA) was performed with the general linear model (GLM) procedure of statistical software package SPSS 18.0 (International Business Machines Corporation, USA). The statistical model included sources of variation due to year, treatment and interaction between year and treatment. When differences were found, one-way analysis of variance was performed to evaluate the effects on the studied parameters based on the least significant differences (LSD) at the 0.05 probability level.

\section{Results}

\subsection{Field experiment (Exp. 1)}

The two years of experimentation yielded very similar results for plant growth under each treatment, with no significant differences in measured biomass and grain yield (Table 2). While dynamics of some parameters at various stages were different between 2013 and 2014, no significant differences were found for whole-season data regarding general root zone average soil water content or total water balance components including water input, water storage, deep drainage, evaporation or transpiration, except runoff (Table 2). Furthermore, calculated WUE was also statistically the same for the two years (Table 2). Therefore, the data regarding runoff in 2013 and 2014 are presented separately, and only the dynamics of root zone average soil water content in 2013 or the average of other parameters in the two growing seasons are depicted in this study (Figs. 2-5 and Table 3). For all of the referred parameters, significant difference was found among the three treatments, and interaction was not found between years and treatments except for runoff (Table 2).

\subsubsection{Water input and consumption}

The maximal rooting depth under the three treatments throughout the growing season was nearly identical and equal to $40 \mathrm{~cm}$, and thus the root zone (i.e. the soil layer for water balance calculation) for each treatment was confined to $0-40 \mathrm{~cm}$. For each treatment, the dynamics of root zone average soil water content in 2013 are demonstrated in Fig. 2a. Under TPRPS, soil water content was assumed to be saturated except during the drying field peri-

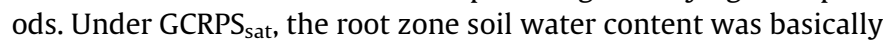
stable except during the drying field periods averaging around $0.409 \mathrm{~cm}^{3} \mathrm{~cm}^{-3}$, corresponding to $87.3 \%$ of the average saturated water content. The root zone average soil water content under GCRPS $_{80 \%}$ fluctuated between 0.237 and $0.469 \mathrm{~cm}^{3} \mathrm{~cm}^{-3}$ with a mean of $0.325 \mathrm{~cm}^{3} \mathrm{~cm}^{-3}$, corresponding to $82.2 \%$ of the average field water capacity $\left(\bar{\theta}_{f}, \mathrm{~cm}^{3} \mathrm{~cm}^{-3}\right)$. With identical precipitation (Fig. 3a), irrigation was significantly different between treatments (Fig. 3b). Average seasonal irrigation to TPRPS was $800 \mathrm{~mm}$, which was 2.6 times of that applied to GCRPS sat $(308.7 \mathrm{~mm})$ and 6.3 times of that to GCPRS $80 \%$ (126.5 mm). Average input water under TPRPS reached $1420 \mathrm{~mm}$, which was 1.5 times of that under GCRPS $(928.7 \mathrm{~mm})$ and 1.9 times of that under GCRPS $_{80 \%}(746.5 \mathrm{~mm})$. 
Table 2

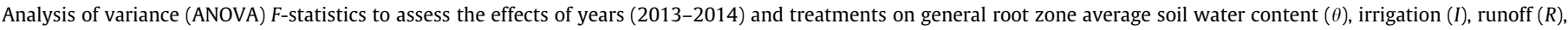

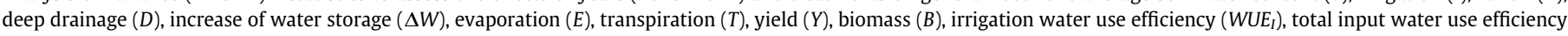
$\left(W U E_{I+P}\right)$ and transpiration water use efficiency $\left(W U E_{T}\right)$ in Exp. 1.

\begin{tabular}{|c|c|c|c|c|c|c|c|c|c|c|c|c|c|}
\hline \multirow[t]{2}{*}{ Source } & \multirow[t]{2}{*}{ DF } & \multicolumn{12}{|c|}{ ANOVA, $F$ value } \\
\hline & & $\theta$ & $I$ & $R$ & $D$ & $\Delta W$ & $E$ & $T$ & $Y$ & $B$ & $W U E_{I}$ & $W U E_{I+P}$ & $W U E_{T}$ \\
\hline Year & 1 & $0.007 \mathrm{~ns}$ & $0.13 \mathrm{~ns}$ & 39.15 & $0.16 \mathrm{~ns}$ & $0.27 \mathrm{~ns}$ & $0.43 \mathrm{~ns}$ & $4.06 \mathrm{~ns}$ & $0.14 \mathrm{~ns}$ & $0.05 \mathrm{~ns}$ & $4.92 \mathrm{~ns}$ & $0.84 \mathrm{~ns}$ & $1.52 \mathrm{~ns}$ \\
\hline Treatment & 2 & $\underbrace{81.38}_{* * *}$ & 146.21 & 16.61 & 103.65 & 64.49 & 759.11 & 7.39 & 9.84 & 8.04 & 181.85 & 197.03 & 19.79 \\
\hline $\begin{array}{l}\text { Year } \times \\
\quad \text { Treatment }\end{array}$ & 2 & $0.007 \mathrm{~ns}$ & $0.08 \mathrm{~ns}$ & 5.14 & $0.31 \mathrm{~ns}$ & $1.94 \mathrm{~ns}$ & $0.21 \mathrm{~ns}$ & $0.83 n s$ & $0.012 \mathrm{~ns}$ & $0.59 \mathrm{~ns}$ & $3.48 \mathrm{~ns}$ & $0.002 \mathrm{~ns}$ & $0.50 \mathrm{~ns}$ \\
\hline
\end{tabular}

Note: DF, degree of freedom

ns: not significant.

Significant at 0.05 probability level.

* Significant at 0.01 probability level.

*** Significant at 0.001 probability level.
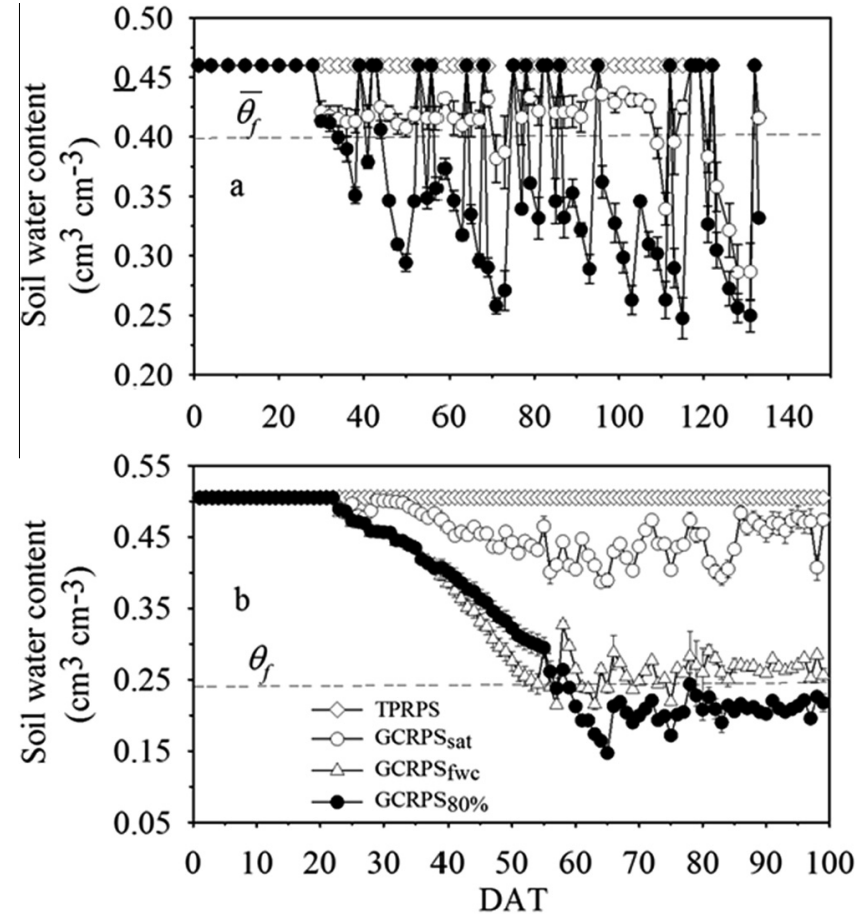

Fig. 2. Dynamics of root zone average soil water content in (a) 2013 of Exp. 1 and (b) Exp. 2 under different treatments (TPRPS, traditional paddy rice production system; GCRPS sat, ground cover rice production system (GCRPS) with nearly saturated water content in root zone; GCRPS $_{\text {fwc }}$, GCRPS with 100-120\% of field water capacity in root zone; GCRPS $80 \%$, GCRPS with $80-100 \%$ of field water capacity in root zone). The discontinuous phase for TPRPS in Exp. 1 was the drying field period without a water layer. Vertical bars indicate standard errors with 3 replicates. DAT means days after transplanting. The dotted line indicates average field water capacity of the two soil layers in Exp. $1\left(\overline{\theta_{f}}\right)$ and the field water capacity in Exp. $2\left(\theta_{f}\right)$.

The average seasonal change in water storage under TPRPS, GCRPS $_{\text {sat }}$ and GCRPS $80 \%$ was $-52.6,-19.4$ and $-42.8 \mathrm{~mm}$, respectively (Fig. 3c). The total seasonal deep drainage under TPRPS averaged $620.3 \mathrm{~mm}$, which was 3.5 times of that under GCRPS $_{\text {sat }}$ $(176.7 \mathrm{~mm})$ and 8.5 times of that under GCRPS $_{80 \%}(73.3 \mathrm{~mm})$. Under GCRPS $_{80 \%}$, deep drainage was similar to that under GCRPS from transplanting to mid-tillering, and was subsequently decreased when less irrigation water was supplied (Fig. 3d). Moreover, upward water flow, i.e. slight water replenishment from deeper soil layers to root zone $(0-40 \mathrm{~cm})$, was found under GCRPS $80 \%$ during the max-tillering and panicle initiation stages. Significant difference was found for runoff between the two years. In 2013, the total runoff under GCRPS $_{\text {sat }}(170.9 \mathrm{~mm})$ and GCRPS $_{80 \%}$
(147.6 mm) was about 2.6 and 2.3 times of that under TPRPS (64.8 mm), respectively (Fig. 3e). Nevertheless, in 2014, the ratio of runoff under GCRPS sat $(83.5 \mathrm{~mm})$ and GCRPS $_{80 \%}(59.7 \mathrm{~mm})$ to that under TPRPS $(47.1 \mathrm{~mm})$ was significantly narrowed to 1.8 and 1.3 , respectively (Fig. 3f). Average seasonal evaporation loss

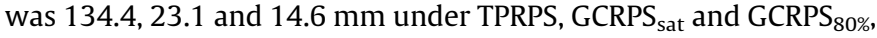
respectively. In comparison to TPRPS, the average evaporation was decreased $82.8 \%$ under GCRPS $_{\text {sat }}$ and $89.1 \%$ under GCRPS $_{80 \%}$ (Fig. $3 g$ ). Totally, the average non-physiological water consumption in Exp. 1 was reduced $59.4 \%$ under GCRPS sat $(307.6 \mathrm{~mm})$ and $80.4 \%$ under GCRPS $_{80 \%}(148.8 \mathrm{~mm})$, and took about $33.1 \%$ and $19.9 \%$ of the corresponding total input water, while under TPRPS $(758.1 \mathrm{~mm}) 53.4 \%$ of input water was non-physiologically consumed.

Transpiration was significantly limited under GCRPS in comparison to TPRPS, while significant differences were not found between GCRPS sat $_{\text {and }}$ GCRPS ${ }_{80 \%}$. The total average transpiration

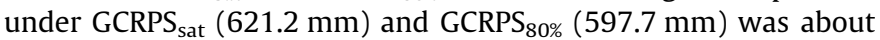
$6.1 \%$ and $9.7 \%$ less than that under TPRPS (661.9 mm). Compared with TPRPS, the transpiration under GCRPS was a little higher during the early growth stage from transplantation to max-tillering, and much lower during the longer later period from panicle initiation to maturity (Fig. 3h).

\subsubsection{Plant growth and water use}

Total biomass of shoots and roots generally increased with plant growth (Fig. 4a). Although no significant difference was

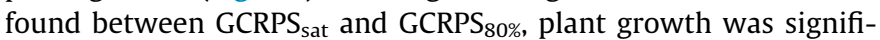
cantly promoted under GCRPS in comparison to TPRPS. However, the positive effect of GCRPS on biomass generally diminished with plant growth. Relative to TPRPS, the mean biomass under GCRPS was enhanced $113.5 \%, 80.9 \%, 49.0 \%, 18.0 \%$ and $15.7 \%$ at midtillering, max-tillering, panicle initiation, anthesis, and maturity stage, respectively. The average yield under GCRPS $\left(0.91 \mathrm{~kg} \mathrm{~m}^{-2}\right)$ was enhanced $11.0 \%$ than that under TPRPS $\left(0.82 \mathrm{~kg} \mathrm{~m}^{-2}\right)$, but no

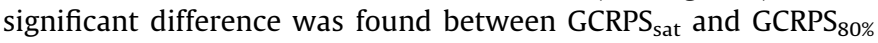
(Table 3).

Compared to TPRPS, $W U E_{I+P}$ and $W U E_{I}$ were respectively significantly improved $70.7 \%$ and $195.1 \%$ under GCRPS $_{\text {sat }}$, and $110.3 \%$ and $608.7 \%$ under GCRPS $_{80 \%}$ (Table 3). In most stages, $W U E_{T}$ was also significantly enhanced under GCRPS sat and $\mathrm{GCRPS}_{80 \%}$, but no significant difference was found between the two GCRPS treatments (Fig. 5a). The $W U E_{T}$ under each treatment initially increased and subsequently decreased with plant growth, with significant enhancement under GCRPS mainly occurring before the panicle initiation stage. In comparison to TPRPS $\left(2.41 \mathrm{~kg} \mathrm{~m}^{-3}\right)$, average general $W_{T}$ under GCRPS $_{\text {sat }}\left(2.97 \mathrm{~kg} \mathrm{~m}^{-3}\right)$ and GCRPS $_{80 \%}$ $\left(3.07 \mathrm{~kg} \mathrm{~m}^{-3}\right.$ ) was enhanced $23.2 \%$ and $27.4 \%$, respectively. 

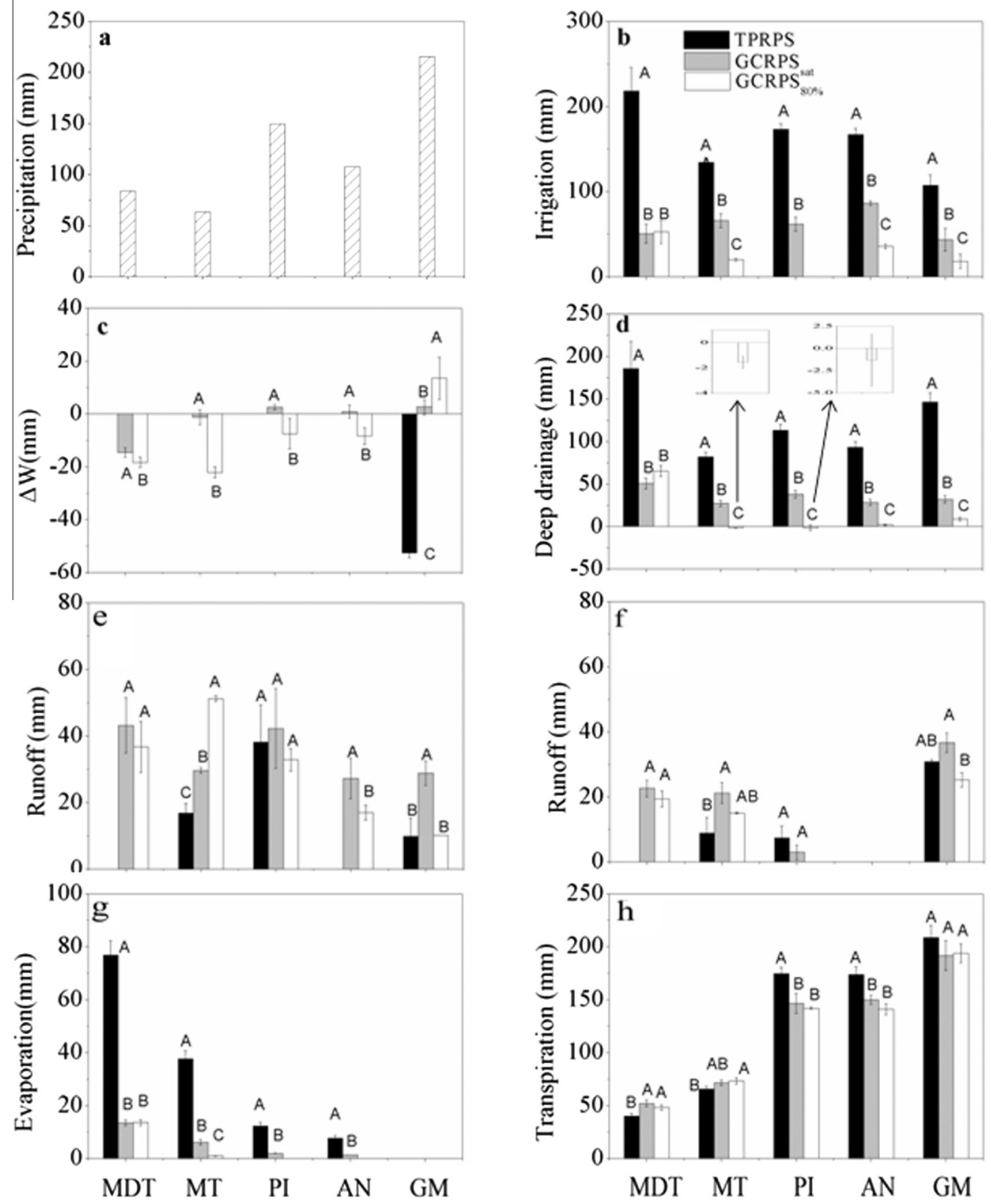

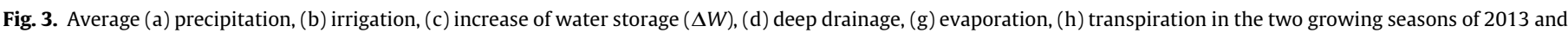

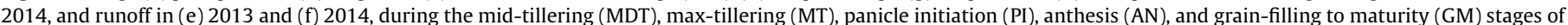

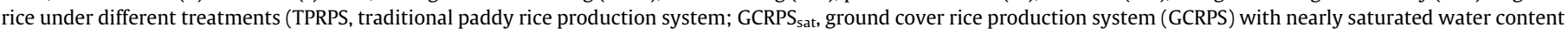

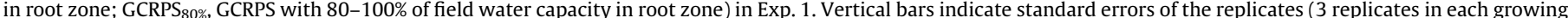

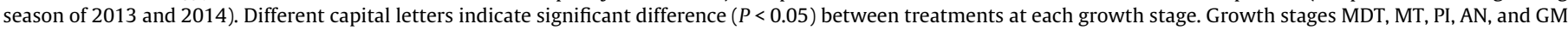

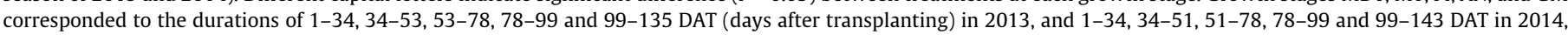
respectively.

\subsection{Greenhouse experiment (Exp. 2)}

During the entire experimental period in Exp. 2, average soil water content of about $0.445 \mathrm{~cm}^{3} \mathrm{~cm}^{-3}$ was consistently maintained under GCRPS $_{\text {sat }}$, corresponding to $88.1 \%$ of the saturated water content (Fig. 2b). Under GCRPS fwc $_{\text {c }}$ and GCRPS $80 \%$, starting at saturation, soil water content declined slowly until 58 DAT, and then was maintained around at an average of $0.263 \mathrm{~cm}^{3} \mathrm{~cm}^{-3}$ (108.2\% of the field water capacity) and $0.217 \mathrm{~cm}^{3} \mathrm{~cm}^{-3}$ (89.3\% of the field water capacity), respectively. The total transpiration

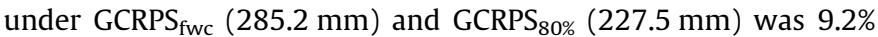
and $27.5 \%$ less than the same value of $314.0 \mathrm{~mm}$ found under TPRPS and GCRPS $_{\mathrm{sat}}$. During the early-tillering and mid-tillering stages, transpiration under GCRPS was significantly higher than that under TPRPS, except GCRPS $_{80 \%}$ during the mid-tillering stage (Fig. 6). During the max-tillering and panicle initiation stages, tran-

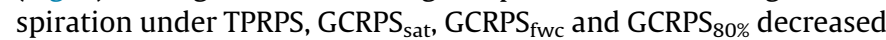
in turn as a function of corresponding difference in soil water content.

The total biomass of shoots and roots under GCRPS sat $_{\text {and }}$ GCRPS $_{\text {fwc }}$ was consistently higher than that under TPRPS and GCRPS $_{80 \%}$ (Fig. 4b). For example, at the panicle initiation stage, biomass under TPRPS was $1.33 \mathrm{~kg} \mathrm{~m}^{-2}, 8.8 \%$ greater than for GCRPS $\left(1.45 \mathrm{~kg} \mathrm{~m}^{-2}\right), 1.6 \%$ more than for $\operatorname{GCRPS}_{\mathrm{fwc}}\left(1.35 \mathrm{~kg} \mathrm{~m}^{-2}\right)$, and $10.3 \%$ lower under GCRPS $_{80 \%}\left(1.20 \mathrm{~kg} \mathrm{~m}^{-2}\right)$ compared to TPRPS. During the entire experimental period, the general $W U E_{T}$ under 

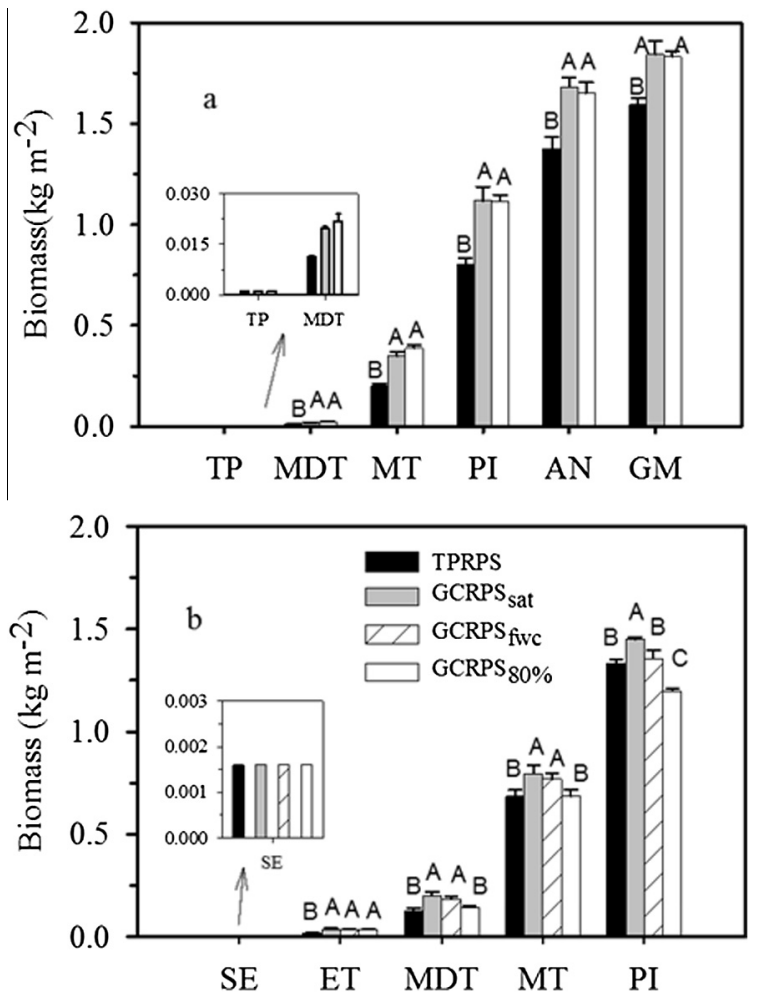

Fig. 4. Dynamics of biomass accumulation in (a) Exp. 1 and (b) Exp. 2 under TPRPS (traditional paddy rice production system), GCRPS sat (ground cover rice production system (GCRPS) with nearly saturated water content in root zone), GCRPS fwc $_{\text {(GCRPS }}$ with $100-120 \%$ of field water capacity in root zone) and GCRPS $80 \%$ (GCRPS with $80-$ $100 \%$ of field water capacity in root zone). Vertical bars indicate standard errors (3 replicates in each growing season of 2013 and 2014 in Exp. 1, and in Exp. 2). Different capital letters indicate significant difference $(P<0.05)$ between treatments at each date. SE: seedling; TP: transplantation; ET: early-tillering; MDT: midtillering; MT: max-tillering; PI: panicle initiation; AN: anthesis; GM: grain-filling to maturity. Growth stages TP, MDT, MT, PI, AN and GM corresponded to 1, 34, 53, 78, 99 and 135 DAT (days after transplanting) in 2013 and 1, 34, 51, 78, 99 and 143 DAT in 2014, respectively, in Exp. 1, while in Exp. 2, SE, ET, MDT, MT and PI stood for 22, 39, 59, 79 and 99 DAT, respectively.

TPRPS was $3.69 \mathrm{~kg} \mathrm{~m}^{-3}$, while it was increased $16.8 \%\left(4.31 \mathrm{~kg} \mathrm{~m}^{-3}\right)$, $23.2 \%\left(4.55 \mathrm{~kg} \mathrm{~m}^{-3}\right)$ and $31.9 \%\left(4.87 \mathrm{~kg} \mathrm{~m}^{-3}\right)$ under GCRPS $_{\mathrm{sat}}$, GCRPS $_{\text {fwc }}$ and GCRPS $80 \%$, respectively (Fig. 5b).

\section{Discussion}

\subsection{Water consumption}

When losses included runoff and deep drainage (Exp. 1), average irrigation savings reached $61.4 \%$ under GCRPS $_{\text {sat }}$ and $84.2 \%$ under GCRPS $_{80 \%}$, which agreed well with previously published findings of $70-80 \%$ for GCRPS (Lin et al., 2002; Huang et al., 2003; Fan et al., 2005; Liu et al., 2005; Tao et al., 2006; Li et al., 2007; Zhang et al., 2008). In Exp. 2, with no runoff or deep drainage, savings in the remaining water consumption components were still substantial, ranging from $12.2 \%$ under GCRPS sat, $24.4 \%$ under GCRPS fsw $_{\text {, }}$, to $45.6 \%$ under GCPRS $80 \%$.

\subsubsection{Non-physiological water consumption}

Under each treatment in Exp. 1, the main change in water storage was found at the end of the growing season as the field dried (Fig. 3c). As a popular measure to control soil water, drying before harvest has no obvious impact on rice production, but is beneficial for saving water and convenient for harvesting grain (Yang and Zhang, 2010).
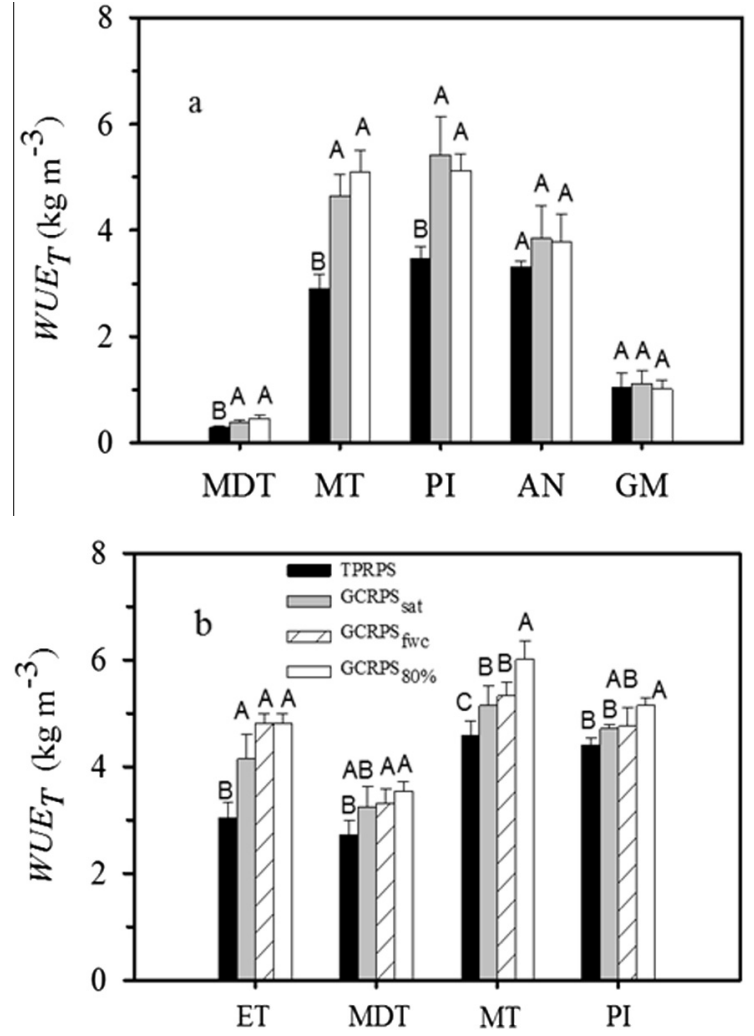

Fig. 5. Water use efficiencies based on transpiration $\left(W U E_{T}\right)$ in (a) Exp. 1 and (b) Exp. 2 under TPRPS (traditional paddy rice production system), GCRPS sat $_{\text {(ground }}$ cover rice production system (GCRPS) with nearly saturated water content in root

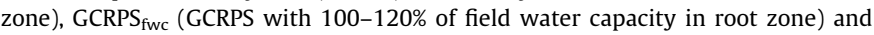
GCRPS $_{80 \%}$ (GCRPS with $80-100 \%$ of field water capacity in root zone). Vertical bars indicate standard errors of the replicates (3 replicates in each growing season of 2013 and 2014 in Exp. 1, and in Exp. 2). Different capital letters indicate significant difference $(P<0.05)$ between treatments at each growth stage. ET: early-tillering; MDT: mid-tillering; MT: max-tillering; PI: panicle initiation; AN: anthesis; GM: grain-filling to maturity. Growth stages MDT, MT, PI, AN and GM corresponded to the durations of $1-34,34-53,53-78,78-99$ and 99-135 DAT (days after transplanting) in 2013, and 1-34, 34-51, 51-78, 78-99 and 99-143 DAT in 2014, respectively, in Exp. 1. In Exp. 2, ET, MDT, MT and PI stood for 22-39, 39-59, 59-79 and 79-99 DAT, respectively.

Table 3

Grain yield and water use efficiencies based on irrigation $\left(W U E_{I}\right)$ and total input water $\left(W U E_{I+P}\right)$ in Exp. 1. TPRPS, the traditional paddy rice production system; $\mathrm{GCRPS}_{\text {sat }}$, the ground cover rice production system (GCRPS) with nearly saturated water content in root zone; GCRPS $80 \%$, the GCRPS with $80-100 \%$ of field water capacity in root zone. Data are the means \pm standard errors ( 3 replicates in each growing season of 2013 and 2014). Different capital letters indicate significant difference $(P<0.05)$ among treatments.

\begin{tabular}{llll}
\hline Treatments & Yield $\left(\mathrm{kg} \mathrm{m}^{-2}\right)$ & WUE $_{I}\left(\mathrm{~kg} \mathrm{~m}^{-3}\right)$ & WUE \\
\hline TPRPS & $0.82 \pm 0.01 \mathrm{~B}$ & $1.03 \pm 0.05 \mathrm{C}$ & $0.58 \pm 0.02 \mathrm{C}$ \\
GCRPS $_{\text {sat }}$ & $0.92 \pm 0.02 \mathrm{~A}$ & $3.03 \pm 0.21 \mathrm{~B}$ & $0.99 \pm 0.02 \mathrm{~B}$ \\
GCRPS $_{80 \%}$ & $0.91 \pm 0.02 \mathrm{~A}$ & $7.30 \pm 0.47 \mathrm{~A}$ & $1.22 \pm 0.02 \mathrm{~A}$ \\
\hline
\end{tabular}

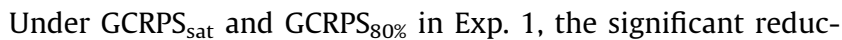
tion in deep drainage and the upward water flow from the deeper soil layer (Fig. 3d) mainly could be credited to the unsaturated soil water status in the $0-40 \mathrm{~cm}$ root zone (Fig. 2a). Under TPRPS, the average proportion of deep drainage to input water was about $43.7 \%$, lower than the value of $57 \%$ estimated by Bouman et al. (2005), likely due to the lower soil hydraulic conductivity of the bottom root zone in the current study (Table 1). Under GCRPS and GCRPS $_{80 \%}$, the proportion of drainage to input water was significantly decreased to $19.0 \%$ and $9.8 \%$, which indicated that deep 


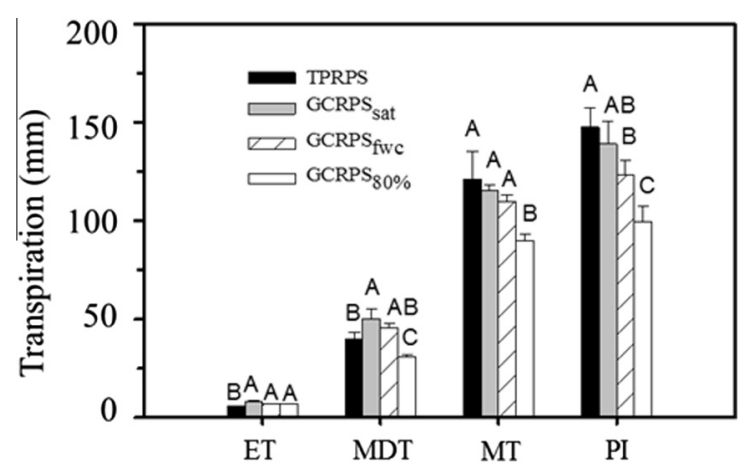

Fig. 6. Transpiration during the early-tillering (ET), mid-tillering (MDT), maxtillering (MT), panicle initiation (PI) stages of rice under different treatments (TPRPS, traditional paddy rice production system; GCRPS $_{\text {sat }}$, ground cover rice production system (GCRPS) with nearly saturated water content in root zone; GCRPS $_{\text {fwc }}$, GCRPS with $100-120 \%$ of field water capacity in root zone; GCRPS $80 \%$, GCRPS with $80-100 \%$ of field water capacity in root zone) in Exp. 2. Vertical bars indicate standard errors with 3 replicates. Different capital letters indicate significant difference $(P<0.05)$ between treatments at each growth stage. ET, MDT, MT and PI stages corresponded to 22-39, 39-59, 59-79 and 79-99 DAT (days after transplanting), respectively.

drainage was still a major pathway for water consumption. Obviously, ignoring the deep drainage under GCRPS (Li et al., 2000; Huang et al., 2003), especially for cases with relatively high soil hydraulic conductivity, would result in great deviation regarding water balance evaluation and irrigation management. For example, an overestimation of $176.7 \mathrm{~mm}$ for transpiration under GCRPS $_{\text {sat }}$ and $73.3 \mathrm{~mm}$ for $\mathrm{GCRPS}_{80 \%}$, would lead to relative errors of $28.4 \%$ and $12.3 \%$, if the corresponding deep drainage was neglected in Exp. 1.

In Exp. 1, distinct differences were found in runoff due to dissimilar rainfall management between the two years. In 2013, since most rainfall was drained off timely to maintain non-flooded conditions under GCRPS, the runoff was significantly higher than that under TPRPS (Fig. 3e). In 2014, although the runoff under GCRPS was still much higher than that under TPRPS, the difference was narrowed due to the fact that a water layer of $1 \mathrm{~cm}$ on the soil beds was permitted under GCRPS in an attempt to more efficiently use rainfall (Fig. 3f). Consequently, in comparison to 2013, when the total runoff in 2014 was only decreased $27.3 \%$ under TPRPS, it was decreased $51.1 \%$ under GCRPS $_{\text {sat }}$ and 59.6\% under GCRPS $_{80 \%}$ (Fig. 3e and $\mathrm{f}$ ). Defined as the ratio of the difference between precipitation and runoff to precipitation (viz. $(P-R) / P$ ), the rainfall use efficiency in 2013 was $89.8 \%$ under TPRPS, while it was only $73.2 \%$ under GCRPS $_{\text {sat }}$ and $76.9 \%$ under GCRPS $_{80 \%}$. In 2014, it was enhanced to $86.1 \%$ under GCRPS $_{\text {sat }}$ and $90.1 \%$ under GCRPS $_{80 \%}$, which was similar to the value of $92.2 \%$ under TPRPS. Therefore, to use rainfall efficiently and keep the effect of increasing soil temperature under GCRPS, which was demonstrated to be very important for rice growth before max-tillering stage (Liu et al., 2013), it may be beneficial to maintain a transient water layer on the soil beds after the max-tillering stage rather than in the early growing season.

During the drying field periods, the total soil surface evaporation from the uncovered soil beds or furrows under TPRPS and GCRPS $_{\text {sat }}$ might be underestimated by substituting $e_{s}(t)$ in Eq. (10) with that under GCRPS $80 \%$, where the soil water content might be lower. During the entire experimental period, the maximal $e_{s}(t)$ under GCRPS ${ }_{80 \%}$ was about $0.35 \mathrm{~mm} \mathrm{~d}^{-1}$ after irrigation. According to Eq. (10), the maximal soil surface evaporation under TPRPS and GCRPS $_{\text {sat }}$ during the drying field periods (about 20 days), therefore, was only about $7 \mathrm{~mm}$ and $1 \mathrm{~mm}$, which was less than $1 \%$ of the corresponding total water consumption and ignorable. Compared to TPRPS, the significant limitation on evaporation under GCRPS $_{\text {sat }}$ and GCRPS ${ }_{80 \%}$ (Fig. $3 \mathrm{~g}$ ) was attributed to the plastic film on the soil beds (Fig. 1). The evaporation component under TPRPS consumed about $9.5 \%$ of the input water, which was a little lower than the $13 \%$ estimated by Bouman et al. (2005) in the Philippines, with the difference likely attributed to different weather conditions. Under GCRPS $_{\text {sat }}$ and GCRPS $_{80 \%}$, evaporation was responsible for only $2.5 \%$ and $2.0 \%$ of the corresponding input water, due to the fact that the surface area of the furrows $\left(11.07 \mathrm{~m}^{2}\right)$, where evaporation occurred, accounted for only $13.1 \%$ of the net area of the plot. Correspondingly, neglecting evaporation (Li et al., 2000;

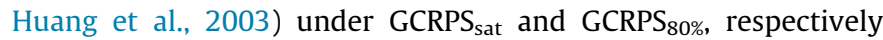
leading to $23.1 \mathrm{~mm}$ and $14.6 \mathrm{~mm}$ overestimation of transpiration with a relative error of $3.7 \%$ and $2.4 \%$, might be acceptable.

\subsubsection{Physiological water consumption}

The estimated seasonal transpiration about $600 \mathrm{~mm}$ for rice in Exp. 1 accorded well with previously published data commonly reporting between 570 and $670 \mathrm{~mm}$ (Bouman and Tuong, 2001; Tuong et al., 2005; Bouman et al., 2007). Under TPRPS, the average seasonal transpiration consumed $46.6 \%$ of the total input water, which was much higher than the value of $30 \%$ estimated by Bouman et al. (2005), with the difference attributed to relatively low levels of deep drainage and evaporation. Under GCRPS sat $_{\text {and }}$ GCRPS $_{80 \%}$, although transpiration was decreased $6.1 \%$ and $9.7 \%$ in comparison to TPRPS, respectively, its proportion to the corresponding input water was raised to $66.9 \%$ and $80.1 \%$ due to the much lower non-physiological water consumption. Since plant transpiration is dominated by leaf area and leaf stomatal conductance, the effects of GCRPS on effective leaf area index $\left(L A I_{e}\right)$ and stomatal conductance of flag leaves were analyzed in this study to interpret the effect of GCRPS on canopy transpiration, even though leaf stomatal conductance can be very sensitive to weather conditions and sampling location (Jarvis, 1976).

Generally, the stomatal conductance of flag leaves was significantly limited under GCRPS and gradually decreased as a function of decreasing average root zone soil water content (Fig. 7a and b). In Exp. 1, the root zone average soil water contents under GCRPS sat $_{\text {at }}$ ranged from above and near the average field water capacity $\bar{\theta}_{f}$ of the two soil layers, to lower than $\bar{\theta}_{f}$ (Fig. 2a). Moreover, most of the soil water contents in the upper root zone $(0-20 \mathrm{~cm})$ were lower than field capacity. Rice might experience water stress when soil water content is less than field capacity (Penning de Vries et al., 1989; Shi et al., 2015). Reflecting this, the measured leaf stomatal conductance under GCRPS $_{\text {sat }}$ was significantly lower than that under TPRPS (Fig. 7a) (Lu et al., 2000; Yang et al., 2007; Zhang et al., 2008, 2009). Under GCRPS $_{80 \%}$, since the root zone average soil water content was lower than $\bar{\theta}_{f}$ much of the time, plants suffered more serious drought stress, leading to the lowest leaf stomatal conductance among the three treatments. In Exp. 2, significant limitation on leaf stomatal conductance was also found under the two film mulched treatments, GCRPS $\mathrm{fwc}_{\mathrm{fw}}$ and $\mathrm{GCRPS}_{80 \%}$. Since the soil water contents at various depths under GCRPS sat $_{\text {were always }}$ higher than field capacity (Fig. 2b), leaf stomatal conductance was found to be similar to that under TPRPS (Fig. 7b).

Elevated soil temperature under GCRPS has been shown to conversely be beneficial to rice tillering and results in larger leaf area (Fan et al., 2005; Liu et al., 2005, 2013; Qu et al., 2012; Tao et al., 2015). In Exp. 1, the $L_{e} I_{e}$ under GCRPS sat and GCRPS $80 \%$ was similar, but it was much higher than that under TPRPS (Fig. 7c). In Exp. 2, a similar trend was observed, however, the difference between TPRPS and GCRPS was small, especially between TPRPS and the seriously stressed treatment of GCRPS $80 \%$ (Fig. 7d). This may not be surprising since the rice grown in the greenhouse did not suffer from low temperatures before mid-tillering stage when the average air temperature was about $23.8^{\circ} \mathrm{C}$. The minimum and 


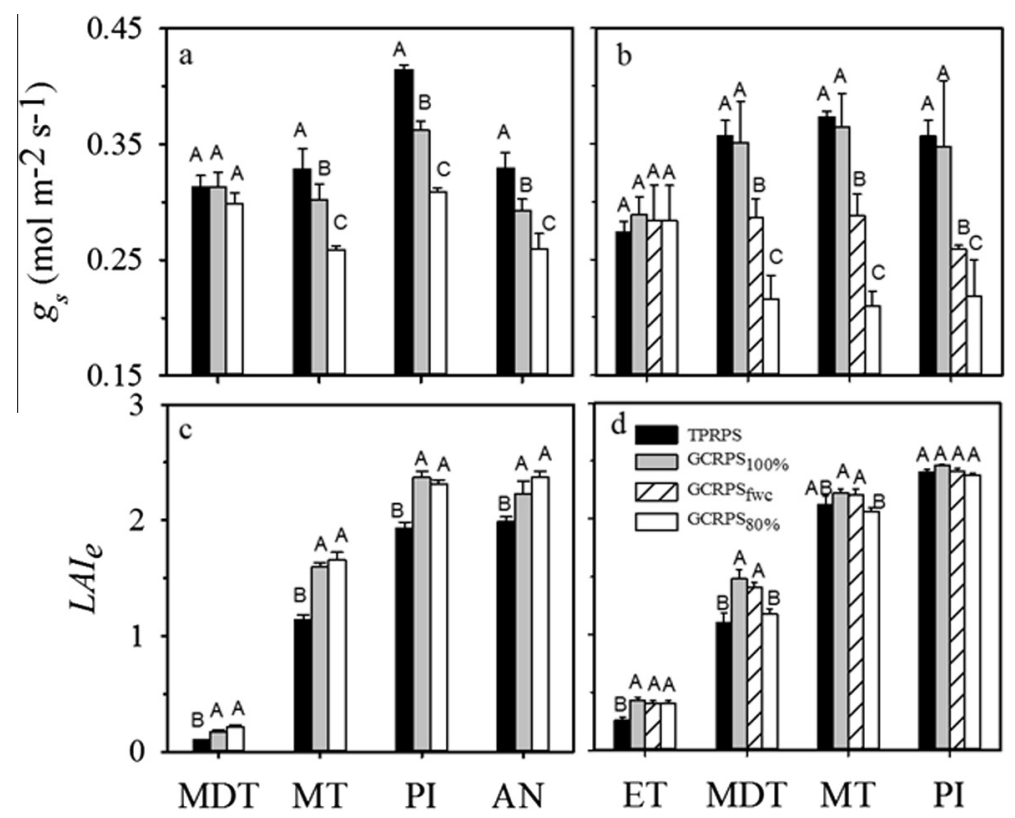

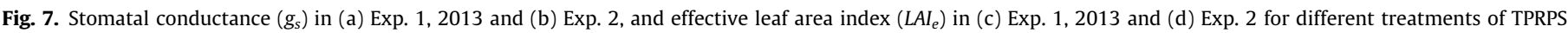

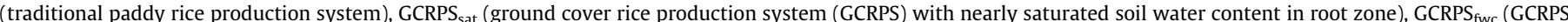

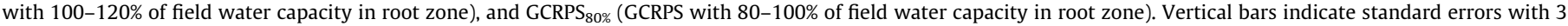

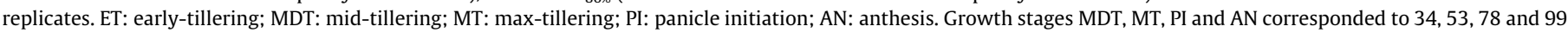
DAT (days after transplanting) in Exp. 1, 2013, while in Exp. 2, ET, MDT, MT and PI stood for 39, 59,79 and 99 DAT.

maximum air temperatures during the early growing season were $18.0^{\circ} \mathrm{C}$ and $30.0^{\circ} \mathrm{C}$ in Exp. 2 compared to $16.0^{\circ} \mathrm{C}$ and $24.9^{\circ} \mathrm{C}$ in Exp. 1. Then again, the soil temperature under GCRPS was only slightly higher than that under TPRPS since soil temperature in the columns was mainly dominated by and approximate to air temperature in the greenhouse. For example, during the early growing season, the average soil temperature at $10 \mathrm{~cm}$ soil depth under GCRPS was only $1.5^{\circ} \mathrm{C}$ higher than that under TPRPS in Exp. 2, while the difference reached $2.8^{\circ} \mathrm{C}$ in Exp. 1 .

Usually, drought stress would restrict both leaf area and stomatal conductance, leading to reduced transpiration (Bouman et al., 2005; Liu et al., 2006). However, an obvious offset between the positive effect of GCRPS on $L A I_{e}$ and the negative effect on leaf stomatal conductance was observed due to the additional impact of increase in soil temperature besides water stress (Fig. 7). From transplanting to max-tillering stage, the positive effect of GCRPS on $L A I_{e}$ exceeded the negative effect on stomatal conductance and thus enhanced plant transpiration. At mid-tillering stage of rice, $L A I_{e}$ under GCRPS $80 \%$ was increased $120.0 \%$ while leaf stomatal conductance was decreased only 3.3\% compared to TPRPS in Exp. 1 (Fig. 7), leading to a $25.6 \%$ enhancement in plant transpiration (Fig. 3h). Nevertheless, significant reduction in plant transpiration was found under GCRPS from panicle initiation and anthesis stage, when the negative effect of GCRPS on leaf stomatal conductance was dominant. At panicle initiation stage of rice in Exp. 2, $L A I_{e}$ under GCRPS $_{\mathrm{fwc}}$ was only increased $0.4 \%$ while leaf stomatal conductance was decreased $27.8 \%$ (Fig. 7 ), leading to a $32.4 \%$ reduction in plant transpiration (Fig. 6). From grain-filling to maturity stage, the difference of plant transpiration between GCRPS and TPRPS was not significant (Fig. 3h). Seasonally, the significant limitation on transpiration under GCRPS indicated that the negative influence of water stress on leaf stomatal conductance overcame the positive influence of plastic film on leaf area.

\subsection{Water use efficiency}

In both experiments, the WUEs based on transpiration $\left(W U E_{T}\right)$, irrigation $\left(W U E_{I}\right)$, and input water $\left(W U E_{I+P}\right)$ generally increased with decreasing root zone average soil water content (Fig. 5 and Table 3). The significant improvement in WUE under GCRPS was attributed to combined enhancement in plant growth and reduction in water consumption.

Under GCRPS, although soil water content was much lower than that under TPRPS (Fig. 2), similar to $L A I_{e}$, the biomass (Fig. 4) was significantly higher due to the increased soil temperature (Liu et al., 2013; Tao et al., 2015) except GCRPS ${ }_{80 \%}$ in Exp. 2, where the negative effect of water stress dominated. Under GCRPS $_{80 \%}$ in Exp. 1, the root zone average soil water content sharply fluctuated between $80 \%$ of the averaged field water capacity and saturation (Fig. 2a), which indicated that plants might only have suffered short-term water stress (Shi et al., 2015). Under GCRPS ${ }_{80 \%}$ in Exp. 2 , the root zone average soil water content was steadily maintained at $89.3 \%$ of field water capacity (Fig. 2b), thus the plants may have been exposed to sustained water stress, which would in turn restrain plant growth and lead to lower biomass (Fig. 4b). Accompanied by limitations on plant transpiration (Figs. 3h and 6), the general enhancement of biomass under GCRPS (Fig. 4) resulted in higher $W U E_{T}$ (Fig. 5). The most significantly elevated $W U E_{T}$ occurred during the vegetative stage (from transplanting to panicle initiation) rather than the reproductive stage (from anthesis to maturity), likely due to excessive growth during the vegetative period under GCRPS readily resulting in nitrogen deficiency during the reproductive stage (Qu et al., 2012; Tao et al., 2014). As an indicator of $W U E_{T}$, stable carbon isotope composition $\left(\delta^{13} \mathrm{C}\right)$ of leaves can provide a time-integrated measurement of a plant's transpiration efficiency, which reflects the averaged ratio of intercellular $\mathrm{CO}_{2}$ and atmospheric $\mathrm{CO}_{2}$ over a period (Farquhar and Richards, 1984; Ehleringer et al., 1993). In the two experiments, the improvement of $W U E_{T}$ under GCRPS indicated that less physiological water consumption brought more photosynthetic products, which also could be further validated by the significant correlation between $W U E_{T}$ and $\delta^{13} \mathrm{C}$ of plant leaves (Fig. 8). Fig. 8 indicated that $\delta^{13} \mathrm{C}$ significantly increased with increasing $W U E_{T}$, and almost all the values of $\delta^{13} \mathrm{C}$ under GCRPS were larger than those under TPRPS as a function of root zone average soil water content. 

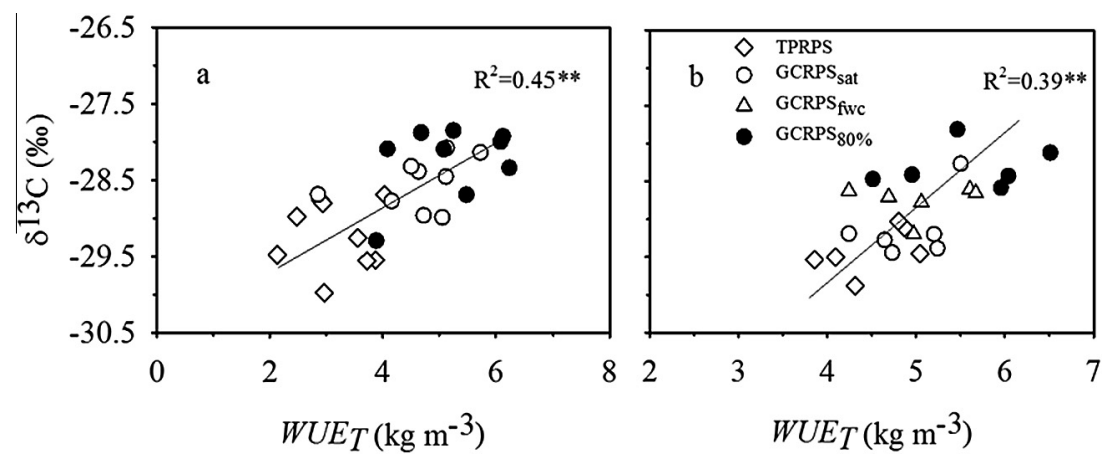

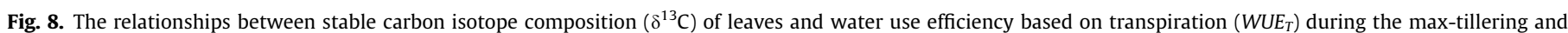

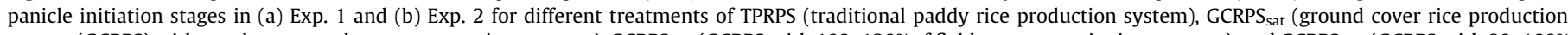

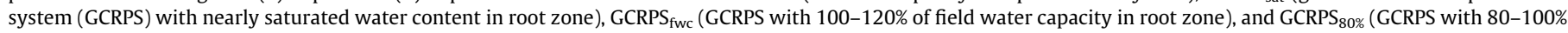
of field water capacity in root zone).

\section{Table 4}

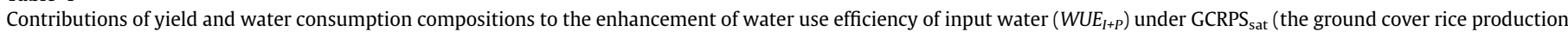

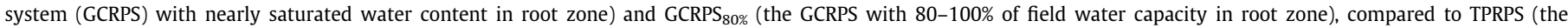
traditional paddy rice production system) in Exp. 1.

\begin{tabular}{|c|c|c|c|c|c|c|}
\hline Treatments & Yield (\%) & Increase of water storage (\%) & Runoff (\%) & Drainage (\%) & Evaporation (\%) & Transpiration (\%) \\
\hline GCRPS $_{\text {sat }}$ & 19.4 & -3.7 & -7.5 & 73.3 & 13.8 & 4.7 \\
\hline GCRPS $_{80 \%}$ & 13.2 & -0.8 & -3.7 & 74.7 & 11.0 & 5.6 \\
\hline
\end{tabular}

In addition to the effective leaf area index and biomass, grain yield under GCRPS was also significantly raised, but no significant difference was found between GCRPS sat and GCRPS $80 \%$ (Table 3). This result was consistent with the reported yield enhancement of $10-18 \%$ under GCRPS from another field experiment (Qu et al., 2012) and a regional scale investigation under real farming conditions managed by farmer households themselves (Liu et al., 2013) in other sites of Shiyan, Hubei Province. Furthermore, compared to TPRPS, the significant improvement in $W U E_{I+P}(70.7-110.3 \%)$ and WUE $E_{I}$ (194.2-608.7\%) under GCRPS (Table 3) also was confirmed by many other previous studies with the ranges of $70-106 \%$ and 273-520\%, respectively (Fan et al., 2005; Liu et al., 2005; Tao et al., 2006, 2015; Li et al., 2007; Xu et al., 2007; Zhang et al., 2008).

The individual contribution of specific factors (e.g. yield, runoff, drainage, evaporation, transpiration and increase of water storage) for the enhancement of $W U E_{I+P}$ from TPRPS to GCRPS was analyzed. Firstly, according to Eqs. (1) and (5), the WUE of input water under TPRPS was expressed as:

$W U E_{I+P}=F_{1} / \sum_{i=2}^{6} F_{i}$

where $F_{i}(i=1,2, \ldots, 6)$ was used to represent $Y, T, R, E, D$, and $\Delta W$, respectively, viz. $F_{1}=Y, F_{2}=T, \ldots$, and $F_{6}=\Delta W$. Secondly, the WUE of input water under TPRPS was re-calculated by substituting the $i$ th factor in Eq. (11) with the corresponding data under GCRPS, labeled as $W U E_{I+P}^{i}$. Finally, the contribution of the $i$ th factor to the enhancement of $W U E_{I+P}$ from TPRPS to GCRPS $\left(C_{f}^{i}\right)$ was evaluated as:

$C_{f}^{i}=\left(W U E_{I+P}^{i}-W U E_{I+P}\right) / \sum_{i=1}^{6}\left(W U E_{I+P}^{i}-W U E_{I+P}\right) \times 100 \%$

The evaluation results (Table 4) showed that $13.2-19.4 \%$ of the improvement of $W U E_{I+P}$ under GCRPS was attributed to increased yield, while the remaining $80.6-86.8 \%$ was due to decreased water consumption. The reduction in deep drainage was the main contributor to the improvement of $W U E_{I+P}$ under GCRPS with a contribution ratio of $73.3-74.7 \%$, followed by evaporation (11.0-13.8\%) and transpiration (4.7-5.6\%). Runoff ( -7.5 to $-3.7 \%$ effect), and water storage ( -3.7 to $-0.8 \%$ effect) both increased under GCRPS and thus had negative consequences on $W U E_{I+P}$ (Table 4).

\section{Conclusions}

In this study, a two-year field experiment and a greenhouse experiment were conducted to investigate the water-saving characteristics of GCRPS by quantitatively analyzing the components of water consumption and the WUEs in comparison to TPRPS. The results showed that both physiological and non-physiological water consumption in GCRPS were significantly reduced while production level was maintained or even enhanced. Furthermore, evaporation in GCRPS might be negligible, but ignoring the deep drainage would bring about serious deviations in water balance evaluations. Maintenance of a transient thin water layer on the soil beds after the max-tillering stage was shown to more efficiently utilize rainfall in GCRPS. In addition to saving water, plant growth and production in GCRPS were promoted, thus leading to improved WUEs. Some $13-19 \%$ of the enhancement of $W U E_{I+P}$ was attributed to the increase of yield under GCRPS, while 81-87\% came from the decrease of water consumption, especially deep drainage. Due to the significant characteristics in enhancing production and reducing both physiological and non-physiological water consumption, GCRPS, and, most especially, GCRPS ${ }_{80 \%}$ should be suitable for practical application in commercial rice production. However, the dynamics regarding soil water transport and root water uptake, and the physiological mechanism of water-saving in a GCRPS (i.e.: how can less transpiration be correlated with higher production?), still need further research.

\section{Acknowledgements}

This research was supported partly by the National Natural Science Foundation of China (51139006 and 51321001) and the Construction Special for First-class University (4572-18101510). We would like to thank the Agriculture Department of Shiyan for providing working facilities during this cooperation.

\section{References}

Alaoui, A., 2015. Modelling susceptibility of grassland soil to macropore flow. J. Hydrol. 525, 536-546. 
Ali, M.H., Talukder, M.S.U., 2008. Increasing water productivity in crop production-a synthesis. Agric. Water Manage. 95, 1201-1213.

Allen, R.G., Pereira, L.S., Raes, D., Smith, M., 1998. Crop evapotranspiration. Guidelines for computing crop water requirements. FAO Irrigation and drainage paper 56, FAO, Rome, Italy, p. 300

Belder, P., Bouman, B.A.M., Cabangon, R., Lu, G.A., Quilang, E.J.P., Li, Y.H., Spiertz, J.H. J., Tuong, T.P., 2004. Effect of water-saving irrigation on rice yield and water use in typical lowland conditions in Asia. Agric. Water Manage. 65 (3), 193-210.

Belder, P., Spiertz, J.H.J., Bouman, B.A.M., Lu, G., Tuong, T.P., 2005. Nitrogen economy and water productivity of lowland rice under water-saving irrigation. Field Crops Res. 93, 169-185.

Ben-Mehrez, M., Taconet, O., Vidal-Madjar, D., Valencogne, C., 1992. Estimation of stomatal resistance and canopy evaporation during the Hapex-Mobilhy experiment. Agric. Forest Meteorol. 58, 285-313.

Beven, K., 1995. Linking parameters across scales: subgrid parameterizations and scale dependent hydrological models. Hydrol. Proc. 9, 507-525.

Bouman, B.A.M., 2007. A conceptual framework for the improvement of crop water productivity at different spatial scales. Agric. Syst. 93, 43-60.

Bouman, B.A.M., Tuong, T.P., 2001. Field water management to save water and increase its productivity in irrigated lowland rice. Agric. Water Manage. 49, 11 30 .

Bouman, B.A.M., Peng, S., Castañeda, A.R., Visperas, R.M., 2005. Yield and water use of irrigated tropical aerobic rice systems. Agric. Water Manage. 74, 87-105.

Bouman, B.A.M., Feng, L.P., Tuong, T.P., Lu, G.A., Wang, H.Q., Feng, Y.H., 2007. Exploring options to grow rice using less water in northern China using a modelling approach - II. Quantifying yield, water balance components, and water productivity. Agric. Water Manage. 88, 23-33.

Cabangon, R.J., Tuong, T.P., Abdullah, N.B., 2002. Comparing water input and water productivity of transplanted and direct-seeded rice production systems. Agric. Water Manage. 57, 11-31.

Chen, S.K., Liu, C.W., 2002. Analysis of water movement in paddy rice fields(I) experimental studies. J. Hydrol. 260, 206-215.

Crago, R.D., 1996. Conservation and variability of the evaporative fraction during the daytime. J. Hydrol. 180, 173-194.

Crawford, J.W., 1994. The relationship between structure and the hydraulic conductivity of soil. Eur. J. Soil Sci. 45, 493-501.

Ehleringer, J.R., Hall, A.E., Farquhar, G.D., 1993. Stable Isotopes and Plant Carbonwater Relations. Academic Press, London (eds).

Fan, X.L., Zhang, J.P., Wu, P., 2002. Water and nitrogen use efficiency of lowland rice in ground covering rice production system in south China. J. Plant Nutr. 25, $1855-1862$.

Fan, M.S., Liu, X.J., Jiang, R.F., Zhang, F.S., Lu, S.H., Zeng, X.Z., Christie, P., 2005. Crop yields, internal nutrient efficiency, and changes in soil properties in rice-wheat rotations under non-flooded mulching cultivation. Plant Soil 277, 265-276.

FAOSTAT. 2011. Food Agricultural Organization, UN http://faostat.fao.org/.

Farquhar, G.D., Richards, R.A., 1984. Isotopic composition of plant carbon correlates with water-use efficiency of wheat genotypes. Aust. J. Plant Physiol. 11, 539552.

Gardner, W.R., 1958. Some steady state solutions of the unsaturated moisture flow equation with application to evaporation from a water table. Soil Sci. 85, 228232.

Gentine, P., Entekhabi, D., Polcher, J., 2011. The diurnal behavior of evaporative fraction in the soil-vegetation-atmospheric boundary layer continuum. J Hydrometeorol. 12, 1530-1546.

Gerke, H.H., 2006. Preferential flow descriptions for structured soils. J. Plant Nutr. Soil Sci. 169 (3), 382-400.

Hasegawa, S., Eguchi, S., 2002. Soil water conditions and flow characteristics in the subsoil of a volcanic ash soil: Findings from field monitoring from 1997 to 1999. Soil Sci. Plant Nutr. 48, 227-236.

Hsiao, T.C., 1993. Effects of drought and elevated $\mathrm{CO}_{2}$ on plant water use efficiency and productivity. In: Jackson, M.B., Black, C.R. (Eds.), Interacting stresses on plants in a changing climate. Spingger-Verlag, Berlin, pp. 435-465.

Huang, X.Y., Xu, Y.C., Shen, Q.R., Zhou, C.L., Yin, J.L., Dittert, K., 2003. Water use efficiency of rice crop cultivated under water logged and aerobic soil mulched with different materials. J. Soil Water Conserv. 17, 140-143 (in Chinese with english abstract).

IRRI, 2011. International Rice Research Institute, Los Banos, Laguna, Philippines http://irri.org/news-events/hot-topics/international-landacquisition-for-riceproduction? print=1\&tmpl=component. Accessed November 10, 2011.

Jarvis, P.G., 1976. The interpretation of the variations in leaf water potential and stomatall conductance found in canopies in the field. Philos. Transpirations R Soc. London, Series B, Biol. Sci. 273, 593-610.

Koestel, J., Larsbo, M., 2014. Imaging and quantification of preferential solute transport in soil macropores. Water Resour. Res. 50, 4357-4378.

Li, R.C., Peng, S.Z., Wang, Y.L., Zhang, Y.M., Yu, J.H., 2000. Water requirement of dryland rice under plastic film mulch. J. Irrig. Drain. 19 (3), 24-28 (in Chinese with english abstract).

Li, Y.S., Wu, L.H., Zhao, L.M., Lu, X.H., Fan, Q.L., Zhang, F.S., 2007. Influence of continuous plastic film mulching on yield, water use efficiency and soil properties of rice fields under non-flooding condition. Soil Till. Res. 93 (2), 370378.

Lin, S., Dittert, K., Tao, H.B., Kreye, C., Xu, Y., Shen, Q.R., Fan, X., Sattelmacher, B. 2002. The ground-cover rice production system (GCRPS): a successful newapproach to save water and increase nitrogen fertilizer efficiency? In: Bouman, B.A.M. Hengsdijk, H., Hardy, B., Bindraban, P.S., Tuong T.P. Ladha, J.K. (Eds.), Water-wise Rice Production: Proceedings of the International Workshop on Water-wise Rice Production, Los Banos, Philippines. IRRL, Los banos, Philippine, pp. 187-196, 8-11 April.

Liu, X.J., Ai, Y.W., Zhang, F.S., Lu, S.H., Zeng, X.Z., Fan, M.S., 2005. Crop production, nitrogen recovery and water use efficiency in rice-wheat rotation as affected by non-flooded mulching cultivation (NFMC). Nutr. Cycl. Agroecosys. 71 (3), 289299.

Liu, F.L., Shahnazari, A., Andersen, M.N., Jacobsen, S.E., Jensen, C.R., 2006. Physiological responses of potato (Solanum tuberosum L.) to partial root-zone drying: ABA signalling, leaf gas exchange, and water use efficiency. J. Exp. Bot. 57 (14), 3727-3735.

Liu, M.J., Lin, S., Dannenmann, M., Tao, Y.Y., Saiz, G., Zuo, Q., Sippel, S., Wei, J.J., Cao, J., Cai, X.Z., 2013. Do water-saving ground cover rice production systems increase grain yields at regional scales? Field Crops Res. 150, 19-28.

Lu, J., Ookawa, T., Hirasawa, T., 2000. The effects of irrigation regimes on the water use, dry matter production and physiological responses of paddy rice. Plant Soil 223, 207-216.

Peng, S.Z., Shen, K.R., Wang, X.C., Liu, J., Luo, X., Wu, L., 1999. A new rice cultivation technology: plastic film mulching. Int. Rice Res. Notes 24 (1), 9-10.

Penning de Vries, F.W.T., Jansen, D.M., ten Berge, H.F.M., Bakema, A., 1989. Simulation of ecophysiological processes of growth in several annual crops. In: Simulation Monographs, 29, IRRI, Los Bafios and Pudoc, Wageningen, p. 271.

Qin, J.T., Hu, F., Zhang, B., Wei, Z.G., Li, H.X., 2006. Role of straw mulching in noncontinuously flooded rice cultivation. Agric. Water Manage. 83, 252-260.

Qiu, G.Y., Wang, L.M., He, X.H., Zhang, X.Y., Chen, S.Y., Chen, J., Yang, Y.H., 2008. Water use efficiency and evapotranspiration of winter wheat and its response to irrigation regime in the north China plain. Agric. Forest Meteorol. 148, 18481859.

Qu, H., Tao, H.B., Tao, Y.Y., Liu, M.J., Shen, K.R., Lin, S., 2012. Ground cover rice production system increases yield and nitrogen recovery efficiency. Agron. J. 104, 1399-1407.

Romano, N., Santini, A., 2002. Water retention and storage: Field-field water capacity. In: Dane, J.H., Topp, G.C. (Eds.), Methods of Soil Analysis. Part 4. SSSA Book Ser. No. 5. SSSA, Madison, WI. pp. 723-729.

Schneider, K., Ippisch, O., Roth, K., 2010. Numerical study of the evaporation process and parameter estimation analysis of an evaporation experiment. Hydrol. Earth Syst. Sci. 14 (5), 765-781.

Shi, J.C., Yasuor, H., Yermiyahu, U., Zuo, Q., Ben-Gal, A., 2014. Dynamic responses of wheat to drought and nitrogen stresses during re-watering cycles. Agric. Water Manage. 146, 163-172.

Shi, J.C., Li, S., Zuo, Q., Ben-Gal, A., 2015. An index for plant water deficit based on root-weighted soil water content. J. Hydrol. 522, 285-294.

Sudhir, Y., Humphreys, E., Kukal, S.S., Gill, G., Rangarajan, R., 2011. Effect of water management on dry seeded and puddled transplanted rice. Part 2: Water balance and water productivity. Field Crops Res. 120, 123-132.

Tao, H.B., Brueck, H., Dittert, K., Kreye, C., Lin, S., Sattelmacher, B., 2006. Growth and yield formation of rice (Oryza sativa L.) in the water-saving ground cover rice production system (GCRPS). Field Crops Res. 95, 1-12.

Tao, Y.Y., Qu, H., Li, Q.J., Gu, X.H., Zhang, Y.N., Liu, M.J., Guo, L., Liu, J., Wei, J.J., Wei, G. J., Shen, K.R., Dittert, K., Lin, S., 2014. Potential to improve N uptake and grain yield in water saving ground cover rice production system. Field Crops Res. 168, 101-108.

Tao, Y.Y., Zhang, Y.N., Jin, X.X., Saiz, G., Guo, L., Liu, M.J., Shi, J.C., Zuo, Q., Tao, H.B., Butterbach-Bahl, K., Dittert, K., Lin, S., 2015. More rice with less water evaluation on yield and resource use efficiency in ground cover rice production system with transplanting. Eur. J. Agron. 68, 13-21.

Tso, T.C., 2004. Agriculture of the future. Nature 428, 215-217.

Tuong, T.P., Bouman, B.A.M., Mortimer, M., 2005. More rice, less water-integrated approaches for increasing water productivity in irrigated rice-based systems in Asia. Plant Product. Sci. 8, 231-241.

van Arkel, H., 1978. Leaf area determinations in sorghum andmaize by the lengthwidth method. Neth. J. Agric. Sci. 26, 170-180.

van Genuchten, M.T., 1980. A closed-form Equation for predicting the hydraulic conductivity of unsaturated soils. Soil Sci. Soc. Am. J. 44, 892-898.

Wang, F.X., Kang, Y.H., Liu, S.P., 2006. Effects of drip irrigation frequency on soil wetting pattern and potato growth in North China Plain. Agric. Water Manage. 79, 248-264.

Xu, G.W., Zhang, Z.C., Zhang, J.H., Yang, J.C., 2007. Much improved water use efficiency of rice under non-flooded mulching cultivation. J. Integr. Plant Biol. 49, 1527-1534.

Yang, J.C., Zhang, J.H., 2010. Crop management techniques to enhance harvest index in rice. J. Exp. Bot. 61 (12), 3177-3189.

Yang, J.C., Liu, K., Wang, Z.Q., Du, Y., Zhang, J.H., 2007. Water-saving and highyielding irrigation for lowland rice by controlling limiting values of soil water potential. J. Integr. Plant Biol. 49, 1445-1454.

Zhang, Z.C., Zhang, S.F., Yang, J.C., Zhang, J.H., 2008. Yield, grain quality and water use efficiency of rice under non-flooded mulching cultivation. Field Crops Res. 108, 71-81.

Zhang, H., Xue, Y.G., Wang, Z.Q., Yang, J.C., Zhang, J.H., 2009. An alternate wetting and moderate soil drying regime improves root and shoot growth in rice. Crop Sci. 49, 2246-2260. 